\title{
The role of energy storage in the uptake of renewable energy: a model comparison approach
}

\author{
Sara Giarola ${ }^{\mathrm{a}}$, Anahi Molar-Cruz ${ }^{\mathrm{b}}$, Kathleen Vaillancourt ${ }^{\mathrm{c}}$, Olivier Bahn ${ }^{\mathrm{d}}$, Luis Sarmiento ${ }^{\mathrm{e}}$, Adam \\ Hawkes $^{\mathrm{a}}$, Maxwell Brown ${ }^{\mathrm{f}}$ \\ ${ }^{a}$ Imperial College London, SW7 2AZ, London \\ ${ }^{b}$ Department of Electrical and Computer Engineering, Technical University of Munich, Arcisstraße 21, 80333, \\ Munich, Germany \\ ${ }^{c}$ ESMIA Consultants, Blainville, Quebec, Canada \\ ${ }^{d}$ GERAD and Department of Decision Sciences, 3000 Chemin de la Côte-Ste-Catherine, Montreeal, Quebec, \\ Canada, H3T $2 A 7$ \\ ${ }^{e}$ German Institute for Economic Research, Mohrenstraße 58, 10117, Berlin, Germany \\ ${ }^{f}$ US Department of Energy - National Renewable Energy Laboratory
}

\begin{abstract}
The power sector needs to ensure a rapid transition towards a low-carbon energy system to avoid the dangerous consequences of greenhouse gas emissions. Storage technologies are a promising option to provide the power system with the flexibility required when intermittent renewables are present in the electricity generation mix. This paper focuses on the role of electricity storage in energy systems with high shares of renewable sources. The study encompasses a model comparison approach where four models (GENeSYS-MOD, MUSE, NATEM, and urbs-MX) are used to analyse the storage uptake in North America. The analysis addresses the conditions affecting storage uptake in each country and its dependence on resource availability, technology costs, and public policies. Results show that storage may promote emissions reduction at lower costs when renewable mandates are in place whereas in presence of carbon taxes, renewables may compete with other low-carbon options. The study also highlights the main modelling approach shortcomings in the modelling of electricity storage in integrated assessment models.
\end{abstract}

Keywords: intermittent renewables, electricity storage, emissions reduction, energy systems modelling

\section{Introduction}

Around two-thirds of global greenhouse gas (GHG) emissions are attributed to fossil fuels (Pachauri and Meyer, 2014). Depending on socio- and techno-economic assumptions, the energy sector needs to reduce emissions between $0.2 \%$ and $7.1 \%$ per year to reach a $66 \%$ likelihood of containing the temperature increase to $1.5^{\circ} \mathrm{C}$ below pre-industrial levels (Rogelj et al., 2015). One of the main strategies to decrease energy sector emissions is to increase the share of renewable (RES) and variable renewable sources (VRES) in the electricity generation mix.

As of 2015, the percentage of renewable energy power sector including hydropower was $25 \%$ (IRENA, 2019); its growth projections vary considerably across studies (Gielen et al., 2019). For

Email address: s.giarola10@imperial.ac.uk (Sara Giarola) 
instance, in its main decarbonization scenario, the International Renewable Energy Agency projects that in 2050, RES and VRES will account for $58 \%$ and $50 \%$ of global power generation, respectively (IRENA and IEA, 2017). The International Energy Agency obtains more conservative shares for VRES (29\%), alongside higher renewable generation (65\%) as a percentage of total global supply. In the United States, estimates project quite a large uptake of variable renewables, reaching up to $50 \%$ of generated electricity by 2050; if all the renewables are included (such as hydropower) the estimate will grow up to $80 \%$ of the generated electricity (Hand, 2012).

Coupling supply and demand for electric power in presence of large shares of VRES is a challenge for the energy systems as the variability of VRES would create sharper ramps, lower turn-downs, and shorter peaks in the generation profile that require the systems to become more flexible in order to remain cost-effective; this implies keeping the decrease in the output of wind and solar (the so-called curtail) low (Cochran et al., 2014). Grid flexibility is the ability of the grid to modify electricity generation and/or consumption patterns in reaction to external changes while providing the service and answering the needs within the energy system (Cochran et al., 2015). Methods to ensure network flexibility, include energy storage, dispatchable generation, renewable curtailment, integration of energy vectors like hydrogen, charging/discharging of electric vehicles, demand-side management, new operating procedures, evolved business models, new market rules, as well as electricity transmission and distribution enhancement (Speirs et al., 2020). These options play an essential role in the future of the energy system. This study focuses on electricity storage. Electricity storage can help achieve grid flexibility by absorbing power when supply is abundant and releasing it when scarce and offers a specific power output for a particular discharge duration. Power output and discharge vary depending on the application: power applications, like frequency regulation and voltage support, require a high power output over a relatively short period (e.g., seconds or minutes). On the other hand, energy applications like arbitrage, peak savings, and load shifting require more extended discharge periods (e.g., hours). ${ }^{1}$

Current global storage capacity is around 190 GW (US Department of Energy, 2019). The vast majority of this capacity belongs to pumped hydropower facilities. Future energy systems require more storage facilities to balance the higher share of intermittent renewables in the upcoming power generation mix (Benato and Stoppato, 2018), especially when the demand for electric power will push capacity to 7,200 GW by 2040 (International Energy Agency, 2014). However, although cost estimations and projections vary widely in the literature (Zakeri and Syri, 2015), energy storage is still a high capital cost investment that requires supportive policies and market mechanisms for its development (International Energy Agency, 2014).

\footnotetext{
${ }^{1}$ Seasonal storage enabling shifting supply and demand of electricity across seasons still involves several issues that do not make it competitive (Guerra et al., 2020).
} 
This paper focuses on the role of energy storage for delivering a low-carbon power sector in the context of the EMF 34 study: North American Energy Trade and Integration. The study uses a model inter-comparison approach with four energy systems models (GENeSYS - MOD, MUSE, $N A T E M$, and urbs $-M X)$. In this way, it provides a comprehensive view on the role of electricity storage which accounts for the dynamics between the energy systems demand of the three countries in the region and their electricity generation when the VRES share grows considerably. The energy systems approach is necessary to account the heterogeneity in each country in terms of socio-economic development trends, energy and costs projections, as well as resource availability. The interplay between storage and renewables is assessed by evaluating scenarios designed to include more than half of the electricity generated with renewable sources. The model inter-comparison methodology allows to broaden the energy futures projections as a result of model diversity and the parametric uncertainties in scenarios with high renewable penetration. Model diversity in the long-term storage development in transitioning energy systems allows to include the diversity dimension of geographical granularity (as we use global economy-wide energy models with national granularity, national economy-wide energy models with high sub-national granularity, and sector-specific models with detailed sub-national granularity), of temporal granularity (as we use national/global energy models with 20-30 timeslices and sector-specific models with hourly granularity), the modelling approach (which spans from optimisation to simulation models), and the energy systems representation (as we include the socio-economic representation typical of economy-wide energy models and detailed power-sector models). Parametric uncertainties include the diversity in the representation of technological costs and policy frameworks (as the models differ in the way low-carbon policies apply to their specific regional granularity). Despite these diversities, model inter-comparison identifies common patterns across the three countries examined, Canada, Mexico, and U.S., which are more robust than single-model exercises, because are confirmed with a plethora of modelling approaches.

\section{Literature review}

Energy storage is crucial for successfully building an energy system model containing large shares of VRES. In their review of 75 energy systems models, Ringkjøb et al. (2018) highlight that the vast majority of them include at least one technological option for electricity storage.

There are a significant number of studies on the social welfare benefits of storage deployment. For instance, Khastieva et al. (2019) propose an optimisation model to ascertain the role of storage on social welfare in a joint transmission and energy storage investment planning model. The authors use a stochastic programming approach to model wind variability in the proposed model. They conclude that energy storage could complement transmission and increase social welfare when the regulatory framework includes the value of non-transmission assets. Other authors emphasise the 
role of storage on electricity prices through demand-side responses. Castagneto Gissey et al. (2019) propose an agent-based power model, ESMA ('Electricity System Management using an Agent-based approach'), to study the role of aggregators in coordinating consumer renewable and energy storage resources in Great Britain. Additionally, they look at the effects of coordination on electricity prices. They suggest that centralized coordination of small-scale storage through aggregators could reduce wholesale electricity prices and their volatility compared to consumer-led decentralized coordination.

Many authors have addressed the interactions between storage and the uptake of renewable sources, but contributions reduce when high renewables uptakes in the energy systems and their links with storage are considered. Burtin and Silva (2015) examine the impact of integrating $60 \%$ of VRES into the generation mix of the European interconnected electricity system. They highlight the need for generation, interconnection infrastructure, and storage deployment. Hansen et al. (2019) use the ENERGYPlan model in a $100 \%$ renewable energy scenario in Germany by 2050. They conclude that a fully renewable system would face challenges regarding the availability of biomass and that thermal plants would require electro-fuels' production as a necessary storage option. Després et al. (2017) optimise long-term scenarios by coupling the European Unit Commitment And Dispatch model (EUCAD) with the Prospective Outlook on Long-term Energy Systems model (POLES). Using both models allows them to include a detailed modeling of storage and demand response with a simple representation of the European electric grid. In their two-degrees policy scenario, carbon prices and the variability of solar promote the development of storage technologies. However, the relation between storage and VRES depends strongly on the scenario analysed. The main influencing factors are the structure of the power system and carbon prices. Segundo Sevilla et al. (2018) optimise a scenario where renewable energy substitutes nuclear power plants in the Zurich power grid. They find that optimal grid operation relies on the deployment of residential and community storage to reduce renewables' curtailment. Bogdanov et al. (2019) optimise a fully renewable worldwide energy system. The authors highlight that storage is a significant element of the power system, supplying $31 \%$ of the demand. Crampes and Trochet (2019) present a conceptual framework to analyse the role of storage in different generation mixes. They conclude that all storage technologies are still too expensive to substitute peak and mid-load generation. Specifically, to eliminate peak load generation, the development of storage supply needs to come hand in hand with the deployment of base-load technologies like nuclear and renewables.

Finally, literature on the effects of storage on emission control strategies provides conflicting results. Lazkano et al. (2017) demonstrate that there is room for carbon emissions reduction in the presence of storage. However, this depends on the competitiveness of renewable energy against conventional electricity generation. Linn and Shih (2019) propose a stylised wholesale power model to examine the role of storage for arbitrage purposes. They show that when renewable genera- 
tion correlates with electricity prices, lower storage costs increase the generation-weighted average electricity price, displacing fossil fuel-fired generation, and reducing the power sector emissions.

In the context of energy systems modelling, model inter-comparison is an effective way to understand energy systems' uncertainties (Weyant, 2004). The method has its strengths in systematically exploring the answers of a set of models to specific perturbations in their inputs, highlighting critical drivers, sources of change, and identifying areas of further research for the modeling community. The analysis becomes less focused on a single scenario containing a vast and complex set of assumptions on policies and technologies and instead focuses on the deviation from the reference. Model intercomparison has been widely used to explore ambiguities, especially in the low-carbon energy systems transition (Grant et al., 2020). Former applications address uncertainties in the cost assumptions of integrated assessment models (Krey et al., 2019), factors triggering and limiting the deployment of crucial low-carbon technologies such as CCS (Koelbl et al., 2014), and the integration of electric vehicles and renewables (Fripp and Dunn, 2018). Focusing on the high level of renewables integration in the United States, Cole et al. (2017) propose a model inter-comparison using four models: the National Energy Modeling System (NEMS), the United States Regional Economy, Greenhouse Gas, and Energy (US-REGEN), the Integrated Planning Model (IPM), and the Regional Energy Deployment System model (ReEDS).They identify spatial and temporal resolution, as well as VRES economics as the real key challenges for energy systems modelling in order to provide a suitable representation of renewables. To the authors' knowledge there is no model inter-comparison study currently referring to energy storage technologies.

Thus, current literature highlights that storage technologies interact dynamically with the energy system but provides only case-specific applications on the conditions favouring the long-term development of storage and emissions reduction. To fill this gap, we propose the first model comparison work to simulate the role of storage in energy transitions and emissions reduction under selected harmonised assumptions in three countries, Canada, Mexico, and USA. We explore the uncertainty range on long-term storage development in transitioning energy systems, due to geographical granularity (as we use national and global models), temporal granularity (as the models adopt different sub-year intervals), policy frameworks (as the three countries differ in their low-carbon policies implementation), technologies, and resource availability (due to the country heterogeneity). The study focuses on assessing the role of storage in long-term scenarios with high renewable uptake. Notably, we explore the conditions under which electricity storage could favour VRES uptake and emissions reduction using four models (GENeSYS-MOD, MUSE, NATEM, and urbs-MX).

The paper is structured as follows. After a preliminary literature survey, the methodology is presented, followed by the scenario narrative and the results discussion. 


\section{Overview of storage technologies}

Storage technologies can be categorised depending on their principle, duration, and discharge time (Gardner et al., 2016). Depending on their principle, there are mechanical (pumped-storage hydropower, compressed air energy storage), thermal (thermo-chemical, sensible thermal, latent thermal storage), chemical (hydrogen storage), electro-chemical (lithium-ion battery), and electrical (super-capacitors). Conditional on duration, electricity storage devices operate as short, medium, and long-term. Their classification depends on the length of time they can store energy, i.e., seconds, days, or months. Depending on discharge time and energy capacity, energy storage devices could shift a small or large amount of energy (i.e., from $\mathrm{kWh}$ to $\mathrm{TWh}$ ) for a short or long duration (from seconds to minutes to a year). For example, a grid-connected storage system co-located with renewables needs to shift energy on an hourly basis, while also supplying high power at other times of the day. As a comparison, to provide adequate reserve capacity, storage devices that can time-shift large amounts of energy over daily periods are also required. Pumped hydro and compressed air energy storage (PHS and CAES) are the most widespread electricity storage technologies. Pumped hydro storage uses gravitational potential energy to save power in periods of excess supply. Traditionally, it pumps water from a lower to a higher elevation when supply is abundant and releases it during periods of higher demand. A disadvantage of PHS is that it requires particular morphologies for its installation, i.e., water resources. CAES uses compressed air to save electricity when supply is high. Unlike PHS, CAES is flexible and can also be installed above ground in compression tanks (ICEF, 2017). Other technologies with lower levels of commercial maturity, i.e., gravity storage although deemed to offer ample storage capacity (Fyke, 2019), have higher investment costs (Gardner et al., 2016). Li-Ion batteries, despite having shown a huge cost reduction over time (from about 1,000 USD per kWh in 2010 down to about 150-200 USD per kWh in 10 years) (Elshurafa, 2020) and being expected to become one of the most cost-efficient stationary options for after 2030 (Schmidt et al., 2019), their use is currently primarily limited to short-duration applications.

Table 1 summarises key techno-economic parameters for selected electricity storage options.

Table 2 summarises top applications for the selected storage types. Due to the high heterogeneity of storage options, specific review articles should be considered to gain a more comprehensive view of storage technologies, attributes, and applications (Koohi-Fayegh and Rosen, 2020).

Additional storage types not mentioned here have been studied; long-term duration of energy storage is an area of increasing research with many innovative options under development (Arpa-e, 2020). 
Table 1: Techno-economics for selected storage technologies from the literature. Investment Cost on energy (InvE) in USD per kWh; Investment Cost on power (InvP) in USD per kW; Efficiency calculated as round-trip efficiency (\%)

\begin{tabular}{lccc}
\hline Benato and Stoppato (2018) & InvE & InvP & Efficiency \\
\hline \hline Pumped Hydro & $5-100$ & & $67-87$ \\
Compressed Air & $2-200$ & & $40-95$ \\
Battery & $120-1,000$ & & $57-85$ \\
Hydrogen & $1-10$ & & $20-50$ \\
\hline ICEF (2017) & InvE & InvP & Efficiency \\
\hline \hline Pumped Hydro & $250-430$ & $500-4,600$ & $50-85$ \\
Compressed Air & $60-130$ & $800-1,500$ & $27-70$ \\
Battery & $290-2000$ & $300-3,500$ & $75-95$ \\
Power to Hydrogen & $440-870$ & $500-750$ & $22-50$ \\
\hline Schmidt et al. (2017) & InvE & InvP & Efficiency \\
\hline \hline Pumped Hydro & 80 & 1129 & 78 \\
Compressed Air & 39 & 871 & 44 \\
Lithium-Ion Battery & 802 & 678 & 86 \\
Hydrogen & 31 & 5417 & 40 \\
\hline Cole and Frazier (2019) & InvE & InvP & Efficiency \\
\hline \hline Lithium-Ion Battery & 355 & & $80-95$ \\
\hline Koohi-Fayegh and Rosen (2020) & InvE & InvP & Efficiency \\
\hline \hline Pumped Hydro & $¡ 300$ & $500-4600$ & $70-80$ \\
Compressed Air & $2-50$ & $400-800$ & $41-75$ \\
Lithium-Ion Battery & 1296 & $1296-1512$ & $85-98$ \\
\hline
\end{tabular}

Notes: Values from (Schmidt et al., 2017) and (Cole and Frazier, 2019) are in USD 2015; for the remaining works, the reference year of the analysis was not clearly disclosed. Cost assumptions used in this study are 2015 values, expressed in 2015 USD per $\mathrm{kW}$.

Table 2: Key applications for selected storage options (IRENA, 2019)

\begin{tabular}{cr}
\hline Type & Key applications \\
\hline \hline PHS & electric energy time shift, electric supply capacity, back start \\
CAES & black start, spinning reserves, electric supply capacity \\
Li-Ion & frequency regulation, electric energy time shift, renewable capacity firming \\
\hline
\end{tabular}

\section{Methodology}

The study presents a model comparison approach to assess the role of storage technologies in the decarbonisation of the North American energy system. We use four models participating in the Energy Modelling Forum EMF 34. The EMF 34 focuses on studying North American energy trade and integration as part of its ongoing renewable transition. Table 3 summarises the main differences in terms of energy systems characterization, solution approach, and trade modeling between all four models. Furthermore, Appendix 10 contains a more detailed description of each model.

The four models use a bottom-up approach, including the definition of the existing stock, salvage value, and age profile for all system power plants; efficiency, capital expenditures, availability, maximum power gradient, minimum load fraction, fuel, output, emissions, operating costs, capital costs, investment constraints, as well as technical and economic life for each technology. A typical investment constraint restricts the maximum total capacity of a technology per year or its maximum growth rate from period to period. Regarding storage technologies, all models have capital and op- 
Table 3: Overview of the main features of the selected models

\begin{tabular}{|c|c|c|c|c|c|}
\hline Model & Regions & Sectors & Trade & Equilibrium & Solution approach \\
\hline $\begin{array}{l}\text { GENeSYS } \\
\text { MOD }\end{array}$ & Mexico & $\begin{array}{c}\text { Power, Transportation } \\
\text { Heat }\end{array}$ & Endogenous & Partial & Cost optimal \\
\hline$M U S E$ & $\begin{array}{l}\text { Mexico } \\
\text { Canada } \\
\text { USA }\end{array}$ & $\begin{array}{c}\text { Power, Industry } \\
\text { Agriculture, Commercial } \\
\text { Residential, Transport }\end{array}$ & Endogenous & Partial & Recursive \\
\hline urbs- $M X$ & $\begin{array}{l}9 \text { Regions } \\
\text { Mexico }\end{array}$ & Power & $\begin{array}{l}\text { US-MEX: fixed, } \\
\text { MEX: endogenous }\end{array}$ & Partial & Cost optimal \\
\hline NATEM & $\begin{array}{l}13 \text { provinces } \\
\text { Canada }\end{array}$ & $\begin{array}{c}\text { Power, Industry } \\
\text { Agriculture, Commercial } \\
\text { Residential, Transport }\end{array}$ & $\begin{array}{l}\text { Optimised } \\
\text { in } \\
\text { Canada }\end{array}$ & Partial & $\begin{array}{l}\text { Maximum } \\
\text { Net } \\
\text { Surplus }\end{array}$ \\
\hline
\end{tabular}

eration costs, charging and discharging phases, and charging and discharging efficiency. In addition, urbs - MX also defines self-discharging efficiency.

Across all models, the technology parametrisation includes the following:

- Existing capacity: existing stock and age profile defined through the commissioning and the decommissioning year

- Efficiency: typically the unit fuel consumption for the technology operation. urbs $-M X$ also models full-load and partial-load operations.

- CAPEX: capital expenditure per unit of technology capacity; in the power sector this would be measured in $\mathrm{kW}$ installed.

- OPEX: unit operating cost per unit of technology output; in the power sector this would be measured in $\mathrm{kWh}$ of generated electricity

- Salvage value: this represents the end-of-life value of a technology

- Weighted average cost of capital: technology interest rate

- Technical life: number of years for the technology operation. in urbs - MX, storage technologies technical life is measured in maximum number of cycles

- Economic life: number of years in which the investment is written off

- Availability: maximum number of plant operating hours in a period compared to the total number of hours in that period

- Maximum power gradient: maximum transition rate from different operating regimes

- Minimum load fraction: minimum generation of technology; in the power sector this would be measured in $\mathrm{kWh}$ of generated electricity 
- Type of commodity used as fuel input

- Type of commodity produced as output; in the power sector it would be electricity

- Investment constraints typically include maximum capacity addition of a technology per period, the maximum total capacity of a technology per year, and the maximum growth rate of the installed capacity from period to period

- Emissions of $\mathrm{CO}_{2}, \mathrm{~N}_{2} \mathrm{O}, \mathrm{CH}_{4}$ per unit of technology activity; in the power sector this is measured in $\mathrm{kg}$ of emissions per $\mathrm{kWh}$ for example

Specifically, storage technologies have these features:

- CAPEX and OPEX can also be expressed per unit of storage output, measured in $\mathrm{kWh}$

- charging and discharging phases are characterised by a number of hours operating at maximum capacity

- the efficiency is the ratio of the energy output over the energy input for the charging (charging efficiency) and the discharging efficiency (discharging efficiency). A self-discharging efficiency is also defined (in urbs $-M X$ ).

The models shared a similarly detailed characterisation of the power sector in terms of technologies (see Table 4); CCS is included in all the models except in urbs-MX. For what concerns storage technologies, PHS and LIB are present across all models. GENeSYS - MOD offers a wider range of options, including also compressed air storage, hydrogen, and heat storage. The stabilisation of the power sector in the grid would greatly benefit from the integration of charging/discharging of electric vehicles, but this option is beyond the scope of this paper.

The model inter-comparison study gathers together global and national models as well as economywide and power-sector specific models whose diversity refers to key sources of uncertainty in the modelling of storage technologies and high renewable uptakes. In fact, the model selection allows to explore the energy storage potentials arising from socio-economic drivers of energy demand, technology developments, implications of aggregated versus more discretised geographical characterisations, and implications of coarser versus more refined time granularity. These diversities contribute to create a robust model inter-comparison where common patterns are more strongly supported by the variety of the modelling approaches. National models, such as $N A T E M$ and urbs $-M X$ have a sub-national granularity which allows modelling at a province or regions of resource availability, costs, policies, and techno-economic parametrisation. Other National economy-wide energy systems models, such as GEneSYS-MOD, presents a granularity detail at a country-level. Global models, 
Table 4: Power sector modelling

\begin{tabular}{|c|c|c|c|c|c|}
\hline Model & Conventional & Renewables & Storage & Demand response & Costs \\
\hline $\begin{array}{l}\text { GENeSYS } \\
\text { MOD }\end{array}$ & $\begin{array}{l}\text { oil, gas, coal } \\
\text { lignite, nuclear } \\
\text { biomass }\end{array}$ & $\begin{array}{l}\text { WOn, WOff, SPR } \\
\text { SPG, CSP, GEO } \\
\text { HSL, HLG, Oc } \\
\text { WOn, WOff, SPR }\end{array}$ & $\begin{array}{c}\text { PHS, LIB } \\
\text { CAES, HYS } \\
\text { HES }\end{array}$ & No & $\begin{array}{l}\mathrm{I}, \mathrm{O} \& \mathrm{M}, \mathrm{F}, \\
\mathrm{CO}_{2} \text { price, } \mathrm{S}\end{array}$ \\
\hline$M U S E$ & $\begin{array}{l}\text { oil, gas, coal } \\
\text { lignite, nuclear }\end{array}$ & $\begin{array}{l}\text { SPG, CSP, GEO } \\
\text { HSL, HLG, Oc } \\
\text { biomass }\end{array}$ & PHS, LIB & No & $\begin{array}{l}\mathrm{I}, \mathrm{O} \& \mathrm{M}, \mathrm{F} \\
\mathrm{CO}_{2} \text { price }\end{array}$ \\
\hline urbs- $M X$ & $\begin{array}{c}\text { oil, gas } \\
\text { coal, nuclear }\end{array}$ & $\begin{array}{l}\text { WOn, SPG, GEO } \\
\text { HSL, HLG, biomass }\end{array}$ & PHS, Li-ion & No & $\begin{array}{l}\mathrm{I}, \mathrm{O} \& \mathrm{M}, \mathrm{F} \\
\mathrm{CO}_{2} \text { price }\end{array}$ \\
\hline$N A T E M$ & $\begin{array}{l}\text { oil, gas, coal } \\
\text { lignite, nuclear } \\
\text { biomass }\end{array}$ & $\begin{array}{c}\text { WOn, WOff, SPR } \\
\text { SPG GEO, HSL } \\
\text { HLG, Oc }\end{array}$ & PHS, Li-ion & $\begin{array}{l}\text { Price-elasticities } \\
\text { of } \\
\text { service demands }\end{array}$ & $\begin{array}{l}\mathrm{I}, \mathrm{O} \& \mathrm{M}, \mathrm{F}, \mathrm{S} \\
\mathrm{CO}_{2} \text { price }\end{array}$ \\
\hline
\end{tabular}

Notes: Renewables include wind onshore (WOn), wind offshore (WOff), solar panel rooftop (SPR), solar panel ground (SPG), concentrating solar panel (CSP), geothermal (GEO), small hydropower (HSL), large hydropower (HLG), tidal (Oc), carbon capture and storage (CCS). Storage technologies include Pumped-hydro (PHS), Battery Lithium-Ion (LIB), Compressed Air Energy (CAES), Hydrogen (HYS), and Heat Storage (HES). Other abbreviations: investment (I), operating and maintenance $(\mathrm{O} \& \mathrm{M}), \mathrm{F}$ (fixed) costs, carbon price $\left(\mathrm{CO}_{2}\right), \mathrm{S}$ (salvage value)

such as MUSE, use regional granularity: the model characterises the world using 28 regions and North America is represented using 3 countries, interlinked by traded energy flows.

For what concerns the temporal characterisation, while power models such as urbs $-M X$, use an hourly-based temporal granularity to describe the energy demand and supply dynamics, economywide energy systems models (such as GENeSYS - MOD, MUSE, and NATEM) reduce the computational burden using a sub-year subdivisions, which aggregates representative hours in a year, called time slices. All the models characterise the availability of renewables specific to their regional granularity using capacity factors calculated on a time slice basis for solar and wind. Capacity factors for hydropower are modelled on hourly, seasonal, time slice, yearly basis respectively in $u r b-M X$, NATEM, GENESYS - MOD, and MUSE.

The temporal and geographical granularity of each model is summarised in Table 5.

Table 5: Model granularity

\begin{tabular}{lcc}
\hline Model & Temporal intermittency & Geographical granularity Renewables \\
\hline NATEM & 4 seasons, 4 intradays & Canada: 13 provinces \\
MUSE & 3 seasons, 4 intradays & Canada, Mexico, USA \\
urbs $-M X$ & 8760 (hours) & Mexico: 9 regions \\
GEneSYS - MOD & 20 time slices & Mexico: 1 region \\
\hline
\end{tabular}

\section{Model comparison}

This study examines the relationship between increases in the uptake of traditional and variable renewable sources and the deployment of storage technologies in North America. 


\subsection{Harmonisation method}

Model inter-comparison studies present several approaches which address differently the dimensions of possible harmonisation (e.g., socio-economic drivers, techno-economic parametrisation, policies). Notably, structural differences across models make unrealistically achievable a full harmonisation across all the dimensions (Krey et al., 2019). This study pursues the principles of a partial harmonisation of the models' inputs, implying that only selected variables were made closely aligned across models, but leaving other assumptions up to the modellers' expert judgment. This methodology allows to obtain a more diverse pattern of future outcomes and can provide more confidence on the scenario results as they would be able to accommodate more the uncertainties of the future energy system. Table 6 shows the detailed of the harmonised input data.

Table 6: Harmonised dimensions

\begin{tabular}{ll}
\hline Socio-economic drivers & Approach \\
\hline NATEM & Based on national source. Electricity demand in Canada consistent with MUSE. \\
MUSE & SSP2 (Riahi et al., 2017) (Dellink et al., 2017) \\
GENeSYS-MOD & Absent. Electric vehicles driving electricity demand \\
urbs $-M X$ & Absent. Electricity demand consistent with MUSE \\
\hline Technologies & Approach \\
\hline Historical emissions & Stock calibration in 2015 \\
Technology suite & Good mapping of the power sector technologies \\
Costs & Not harmonised \\
\hline Policies & Approach \\
\hline Canada & Focus on high impact policies: non-abated coal power station decommissioning \\
Mexico & Clean power generation mandates in GENeSYS-MOD and urbs - MX \\
& Minimum addition of renewables capacities in $M U S E$ \\
\hline
\end{tabular}

\subsection{Scenario description}

Table 7 summarises the main scenarios. The reference scenario (Ref.0) does not allow for storage capacities and optimises the energy system with the baseline assumptions of each modeling team. Ref.1 deviates from Ref.0 by allowing the models to invest in storage technologies.

Table 7: Scenarios

\begin{tabular}{lcccccc}
\hline & Ref.0 & Ref.1 & Ren.0 & Ren.1 & Ctax.0 & Ctax.1 \\
\hline Storage Capacity Additions & $\boldsymbol{x}$ & $\checkmark$ & $\boldsymbol{x}$ & $\checkmark$ & $\boldsymbol{x}$ & $\checkmark$ \\
Increased uptake of renewables & $\boldsymbol{x}$ & $\boldsymbol{x}$ & $\checkmark$ & $\checkmark$ & $\boldsymbol{x}$ & $\boldsymbol{x}$ \\
Carbon Tax & $\boldsymbol{x}$ & $\boldsymbol{x}$ & $\boldsymbol{x}$ & $\boldsymbol{x}$ & $\checkmark$ & $\checkmark$ \\
\hline
\end{tabular}

Due to the inherent differences among models in model inter-comparison frameworks, the promotion of renewables can happen through renewable targets, cost decrements, and carbon taxes (IEA, 2017). Consequently, in addition to the reference scenarios, we model two additional situations. A high RES scenario (Ren.) obtained through renewables mandates and a carbon tax (Ctax.) scenario by increasing the cost of carbon emissions. Each presents two variants excluding (denoted with the code 0 ) or including (indicated with 1) the deployment of storage technologies. 
Table 8 shows the growth in the share of renewable generation and carbon price taxes for the Ren. and Ctax. scenarios.

Table 8: Scenario overview: minimum share of electricity generation from renewables (hydropower, solar, wind) and carbon tax

\begin{tabular}{lcccc}
\hline & 2020 & 2030 & 2040 & 2050 \\
\hline $\begin{array}{l}\text { Share of Renewable Generation } \\
\quad \text { Scenario Ren.0 and Ren.1 }\end{array}$ & $20 \%$ & $30 \%$ & $40 \%$ & $50 \%$ \\
$\begin{array}{l}\text { Carbon tax 2015 USD/t of } \mathrm{CO}_{2} \\
\quad \text { Ctax.0 and Ctax.1 }\end{array}$ & 21.00 & 64.77 & 105.51 & 105.51 \\
\hline
\end{tabular}

Each model has specific assumptions worth mentioning. GENeSYS-MOD linearly retires coal, natural gas, and oil power plants. Every five years, the stock of power facilities decreases by $15 \%$, and, in 2040, the model decommissions the remaining 2015 residual capacity. Moreover, it assumes the following clean energy mandates for Mexico: 2020 - 30\%; $2025-40 \%$; $2030-50 \%$; $2040-60 \%$; $2050-80 \%$. urbs - MX considers the same clean energy mandates of GENeSYS - MOD, sets the limit of hydropower capacity to $20 \%$ higher than the 2015 stock, and constrains the construction of new nuclear facilities. ${ }^{3}$ NATEM uses Canadian regulation regarding coal phase-out. Under this regulation, traditional coal-fired electricity phases out by 2030 and no new plants can be built without carbon abatement technologies. ${ }^{4}$. Finally, MUSE sets hydropower and nuclear limits in Canada. The hydropower capacity cannot be larger than $20 \%$ of its value in 2015 and it restrains nuclear technologies to 1,640 MW. Regulations are summarised in Table 9.

The initial investment costs of storage assumed in this study is reported in Table 10. Table 11 shows the capital costs of storage technologies for the four models throughout the simulation period. Capital costs reductions are more conservative in GENeSYS-MOD and more aggressive in $M U S E$, balancing the higher initial capital expenditures. urbs $-M X$ and $N A T E M$ exhibit quite similar trends lying between GENeSYS - MOD and MUSE.

\section{Results and discussion}

We organise results into two sections. First, we present an overview of the reference scenario for Canada, Mexico, and the USA. We present this section, with a specific focus on the drivers of

\footnotetext{
${ }^{3} G E N e S Y S-M O D$ and urbs - MX consider solar, wind, photovoltaic (rooftop and utility), geothermal, hydro, nuclear, and biomass as clean energies.

${ }^{4}$ Special agreements with some Canadian provinces are also included.
} 
Table 9: Reference: main assumptions

\begin{tabular}{ll}
\hline Model & Regulation \\
\hline GENeSYS-MOD & Fossil phase-out \\
& Clean energy mandates \\
urbs-MX & Large hydropower limit to $20 \%$ higher than 2015 capacity \\
& Nuclear limit to twice the 2015 capacity \\
& Clean energy mandates \\
NATEM & Phase-out of unabated coal-fired electricity by 2030 \\
MUSE & Mexico: Limits on hydropower and nuclear as in urbs $-M X$ \\
& Mexico: approximate clean energy mandates \\
& Canada: Coal phase-out \\
\hline
\end{tabular}

Notes: Mexico's fossil phase-out: linear retirement of coal, natural gas, and oil by $15 \%$ by 2030; full decommissioning by 2040 .

Clean energy mandates in Mexico: Solar, wind, geothermal, hydro, and biomass minimum generation: $30 \%$ in 2020, $40 \%$ in $2025,50 \%$ in $2030,60 \%$ in $2040,80 \%$ in 2050 .

Table 10: Investment Cost on power (InvP) basis (USD per kW)

\begin{tabular}{lcccc}
\hline Invp in this study & $G E N e S Y S-M O D$ & MUSE & NATEM & urbs $-M X$ \\
\hline Lithium-Ion Battery & 695 & 5,300 & & 425 \\
Gas Hydrogen & 851 & & & \\
Gas Methane & 851 & & & \\
Compressed Air & 851 & & & \\
Redox battery & 1758 & 3,200 & 1,011 & 992 \\
Pumped Hydro & 2,126 & 3,200 \\
\hline
\end{tabular}

Notes: Cost assumptions used in this study are 2015 values, expressed in 2015 USD per kW. Costs in MUSE are averaged across the three country regions in North America.

Table 11: Scenario overview: Storage CAPEX reduction from base year

\begin{tabular}{lcccc}
\hline Investment costs & 2020 & 2030 & 2040 & 2050 \\
\hline LIB $(G E N e S Y S-M O D)$ & -0.5 & -0.54 & -0.59 & -0.59 \\
HYS, CAES $(G E N e S Y S-M O D)$ & 0 & -0.11 & -0.15 & -0.25 \\
\hline LIB, PHS $(M U S E)$ & -0.45 & -0.99 & -0.99 & -0.99 \\
LIB, PHS $(N A T E M)$ & -0.43 & -0.69 & -0.74 & -0.77 \\
LIB, PHS (urbs-MX) & -0.39 & -0.6 & -0.74 & -0.74 \\
\hline
\end{tabular}

Notes: As initial costs in $M U S E$ displayed higher starting values, we modelled a cost reduction representing an extreme cases of cost reduction to assess deployment, considering the uncertainty in projected storage costs (Schmidt et al., 2017)

electricity generation in each model. Then, we present the sensitivities from the Ref. (Ren, Ctax) scenario for all three nations. The results contain generation profiles, emissions, and storage capacity for each country. ${ }^{5}$

\subsection{Canada: the role of storage and the resource distribution in the Canadian provinces}

As part of the Paris Agreement, Canada committed to reduce its GHG emissions by $30 \%$ below 2005 levels by 2030. In its Mid-Century Long-Term Low-Greenhouse Gas Development Strategy

\footnotetext{
${ }^{5}$ In the results, "other" represents geothermal and bioenergy (without CCS).
} 
(ECCC, 2016), Canada further defines its overall strategy for reducing climate change impacts, by committing to achieving $70 \%$ to $90 \%$ reductions in GHG emissions by 2050 relative to 2005 . The decarbonisation of the electricity sector appears to be a robust solution in any energy transition pathway that is compatible with the decarbonisation of the Canadian economy. Consequently, any climate change mitigation plan requires the decarbonisation of the power sector. With a systemic and dynamic view of the whole energy system, its complexity, regional diversity, and the integration characteristics of North American markets, MUSE and NATEM provide complementary insights: the former model includes commerce among the North American regions and the latter describes in detail the intra-province trades.

Since the Canadian electricity generation portfolio already includes a substantial proportion of renewables, especially when accounting for its large hydro capacities, an economy-wide carbon tax has a more significant impact on carbon mitigation than renewable targets, promoting more renewables integration while decarbonising the whole energy system. However, the broad Canadian diversity of regional energy systems alongside the uneven distribution of resources, ${ }^{6}$ it is imperative to promote the development of storage technologies that diversify the sources of energy supply for provinces with more limited carbon-free options. These provinces can use the new storage facilities as a back-up for intermittent renewable electricity generation. Currently, no specific plans for further storage deployment exist in Canada, but the cost decrease for battery storage should increase intermittent renewables' energy intake.

\subsubsection{Canada: model comparison results discussion}

The models NATEM and MUSE are used to model Canada's energy system between 2015 and 2050. Tables B2 and B1 show the fraction of RES and VRES over the total generation by period and scenario.

MUSE estimates the power demand by determining the demand for services, which correlates with the SSP2 (Shared Socioeconomic Pathways), available from the IIASA database v1 (Dellink et al., 2017). Technologies operate selecting the fuels depending on their intrinsic response to price variations, and the model determines the electricity generation mix on a merit-order approach based on the levelised costs of each technology. The generation also includes the endogenous modeling of the electricity trade between Canada and the USA. Electricity exports to the USA, estimated to be less than $10 \%$ of Canadian demand per year, does not seem to be affected by the presence of storage; and exports only increase by one percent in 2050, mostly driven by the price difference between the two countries and domestic demand trends.

\footnotetext{
${ }^{6}$ Western provinces are endowed with abundant fossil fuel reserves. At the same time most of the hydro potential is in Quebec.
} 
Until 2040, NATEM projects the demand for energy services using a coherent set of socioeconomic drivers arising from national sources, like the projections of the Canadian National Energy Board (NEB - National Energy Board, 2017), after 2040, the model extrapolates these trends. Under these assumptions, the Canadian gross domestic product (GDP) almost doubles by 2050, and the population grows by about 30\%. These projections form the basis for optimising end-use requirements in the different sectors; however, many other factors are considered, such as future announced projects, degree-day projections, number of households, commercial surface, and gross industrial output. NATEM determines the optimal technology and fuel mix to meet each energy service demand at the minimum cost while respecting policy constraints. Consequently, the reference scenario (Ref.0) already includes the penetration of energy conservation measures and those technologies that are already cost-effective without any additional incentives (regulation or price signal).

Figure 1 shows the power generation results for NATEM and MUSE reference scenarios with (Ref.1) and without (Ref.0) storage technologies. The figure shows the power system's high reliance on hydropower. The VRES generation shows an increasing trend, with the relative uptake of solar and wind, depending on the cost reduction assumptions. Overall, both models show a preference for wind technologies. Fossil generation, apart from gas, decrease in the Ref. scenario. Oil decline reflects inefficiencies in its technologies compared to gas. Coal decline reflects regulations imposing that non-abated coal plants would not be re-built after decommissioning. The models meet most of the additional electricity demand with new gas-fired power plants as the most cost-effective option. The uptake of natural gas is particularly sensitive if specific federal policies, such as the federal carbon tax or the clean fuel standard under development were accounted for (LangloisBertrand et al., 2018; Vaillancourt et al., 2018). Nuclear generation, whose decommissioning is assumed to occur at the end of the project lifetime, tends to decline over time in MUSE, while it is relatively constant in NATEM. NATEM imposes the nuclear refurbishment program proposed by the Ontario government. Consequently, although some atomic reactors reach the end of their life before the end of the modeling horizon, the nuclear power generation capacity remains constant.

In the presence of storage (scenario Ref.1), small variations occur in the generation mix. NATEM replaces the decommissioned storage facilities ensuring a constant capacity over time. As constant storage capacity is available, the model shows a one percent increase in cumulative electricity generation from natural gas. MUSE does not show storage capacity potential, due to high initial capital costs and relies more on the cheapest sources, natural gas.

Figure 2 shows the power generation results for NATEM and MUSE sensitivity scenarios Ren. and Ctax. In NATEM, the imposition of renewable targets (Ren.0) or a carbon tax (Ctax.0) causes the system to substitute natural gas with solar and wind. In MUSE, the sensitivity analysis with 

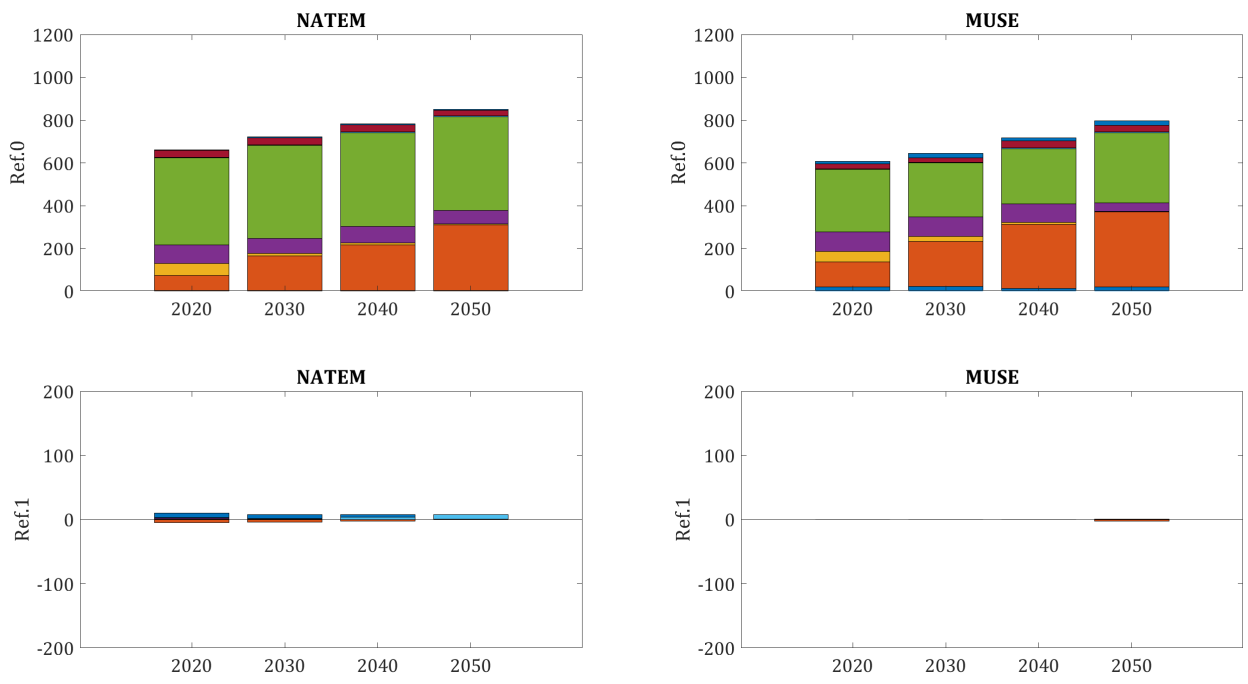

Figure 1: Power generation through 2050 for Canada obtained with NATEM and MUSE in the reference case (Ref.0) and the deviation of Ref.1 from Ref.0 (TWh/y). Blue: oil, Orange: natural gas, Yellow: coal, Purple: nuclear, Green: hydropower, Light blue: solar, Dark red: wind, Dark blue: other

high RES uptake (Ren.0) shows an increase in the generation from RES sources. As the VRES share increases, the model guarantees system reliability with additional nuclear and other renewables (e.g., biomass) capacity. A carbon tax (scenario Ctax.0) is less successful in promoting VRES than the Ren.0 scenario, although the total RES remains high because of hydropower. In general, the natural gas generation sees CCS uptake while it replaces the decommissioned capacity with renewables. Many factors can explain the differences between result series, including solution approaches and assumptions about the future, model structures, level of details, and geographical - temporal resolution. For instance, MUSE endogenously captures the electricity trade between Canada and the United States, while it is fixed exogenously in NATEM following published projections (NEB National Energy Board, 2017). NATEM includes a more detailed representation of the regional energy systems within Canada. It includes dependable capacity constraints for each Canadian jurisdiction with conservative assumptions on the contribution of intermittent renewables to the peak demand. These constraints explain why NATEM shows different intermittent renewable intake than $M U S E$. Each jurisdiction is responsible for self-sufficiency, including guaranteed electrical energy and dependable generating capacity for meeting energy demand at all times, especially during peak periods. There are only three exceptions where high-voltage interconnections can meet the capacity needs of a neighboring jurisdiction; otherwise, provinces cannot use electricity imports. In NATEM the contribution of wind and solar as dependable capacity is limited to $5 \%$ of the peak demand. 

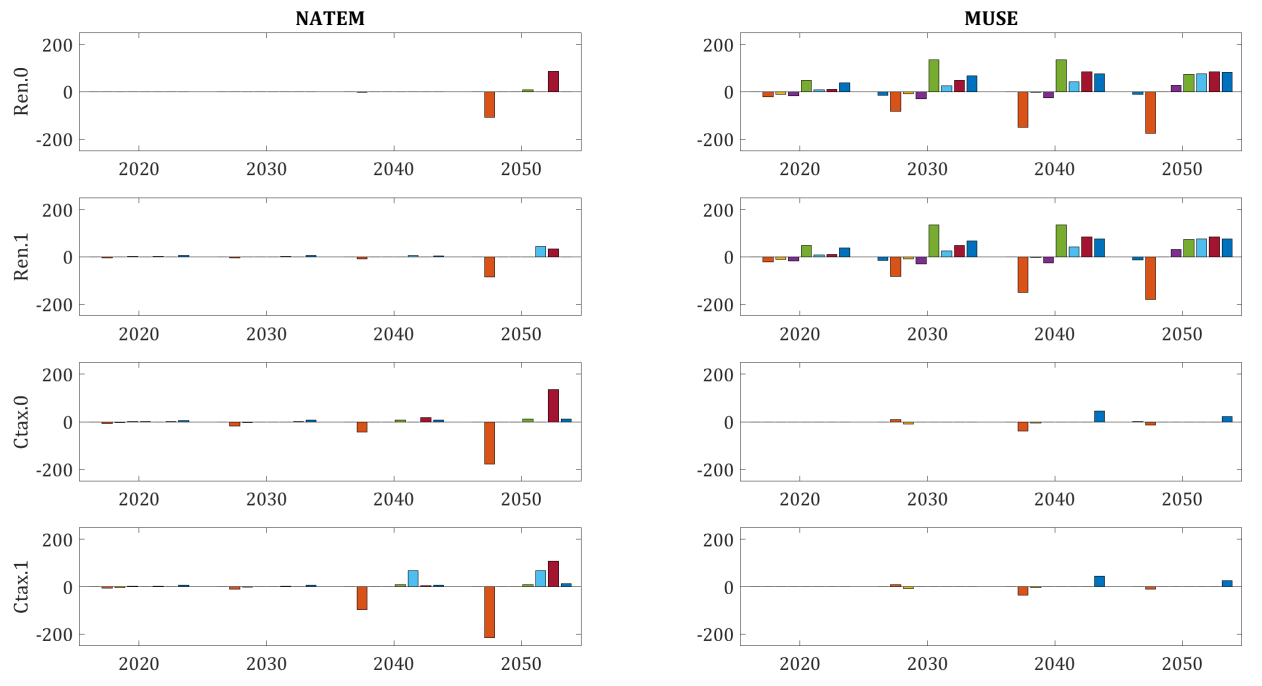

Figure 2: Deviation of power generation through to 2050 for Canada obtained with NATEM and MUSE in the sensitivity cases without and with storage capacity addition (Ren.0, Ren.1, Ctax.0, Ctax.1) compared to the reference (Ref.0) (TWh/y). Blue: oil, Orange: natural gas, Yellow: coal, Purple: nuclear, Green: hydropower, Light blue: solar, Dark red: wind, Dark blue: other

\subsubsection{Canada: sensitivity on storage}

Starting from the reference case, the artificial increase of renewable penetration and the imposition of a carbon tax tend to decrease the generation from fossil fuels in the two models progressively. As the coal and oil decline represents a feature common to all the model outputs, we focus on the differences between the reference and alternative scenarios regarding storage capacity. We show results for the Canadian electricity consumption, power sector emissions, storage capacity, natural gas, and VRES generation. Figures 2, 3, and 4 show consumption, storage capacity, and emissions, respectively.

MUSE reduces natural gas uptake either in presence of high renewables (Ren.) or in presence of a carbon tax (Ctax.). In the high VRES share (Ren.1) scenario, storage can help balance supply and demand; its presence is also accompanied by emissions reductions. Ren.1 is also the scenario with minimum emissions. In a carbon tax scenario (Ctax.1), storage is too expensive to be deployed and the system favours investments in other non-intermittent renewables, such as biomass, whereas the VRES share remains low (Figure 3.

In NATEM, renewable mandates promote the substitution of wind with solar in the Ren.1 scenario. Similarly, in the Ctax.1 case, gas-fired power plants and wind turbines are substituted with solar facilities. The imposition of a carbon tax in combination with storage reduces carbon emissions.

The higher reliance on storage of NATEM compared to MUSE reflects the storage costs (lower 


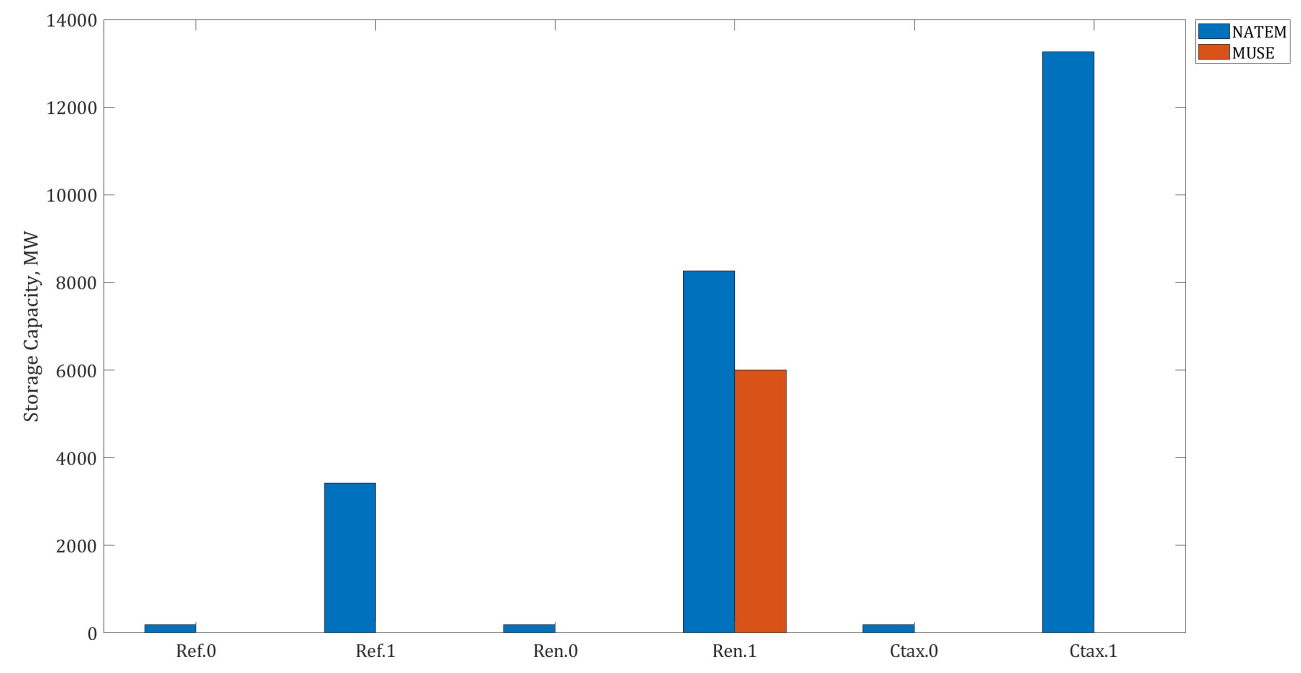

Figure 3: Storage capacity in Canada - NATEM and MUSE models (MW)

Notes: Battery storage is $75 \%, 87 \%$, and $83 \%$ of the total storage capacity respectively in Ref.1, Ren.1., and Ctax.1 in NATEM. In MUSE all the storage capacity is pumped hydro storage.

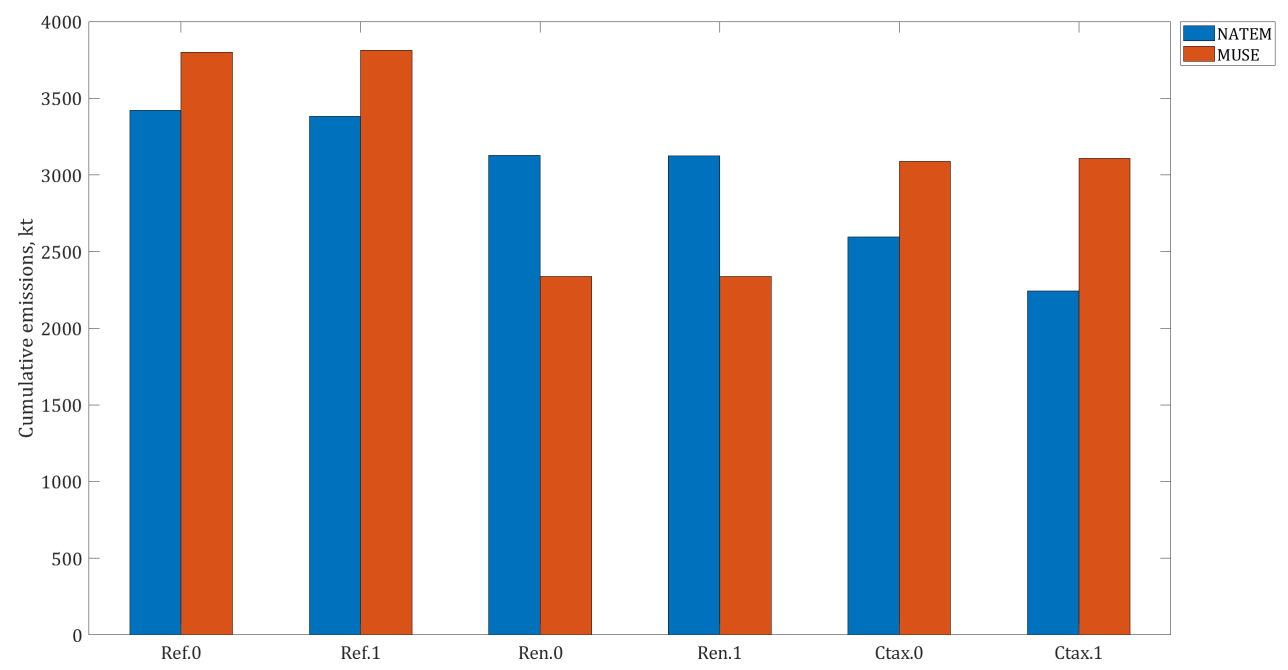

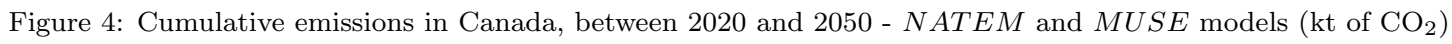

in NATEM), but it also depends on the higher geographical granularity of the model where local availability of renewables are more stringent constraints. NATEM results show that centralised wind farms are necessary for reaching renewable targets in the absence of storage options. When allowed, storage capacity accounts for $8 \mathrm{GW}$ in the high renewable penetration scenario. The existence of storage, promotes the penetration of solar photovoltaic rooftops as battery storage 
options are more cost-effective at the distributed level than pumped storage or other large storage application options. However, the total amount of renewables is not higher when storage options are available and remains driven by the imposition of the renewable penetration targets: they increase from $56 \%$ of the electricity generation mix in the reference case to $68 \%$ (without storage) and $65 \%$ (with storage) in the high renewable penetration scenario.

The imposition of an economy-wide carbon tax leads to more renewable production, i.e., to $76 \%$ without storage and $80 \%$ with storage of the total electricity generation mix to the detriment of gas-fired power generation. Similarly, with the high renewable penetration case, the availability of battery storage options supports more extensive penetration of distributed solar energy. When allowed, storage capacity accounts for $13 \mathrm{GW}$ in the carbon tax scenario. Consequently, the impacts on carbon emissions from electricity generation are greater when the power sector fully decarbonises thanks to net negative mitigation options in some jurisdictions with biomass-fired power combined with carbon capture and storage (BECCS). These results are compatible with some previous studies (Vaillancourt et al., 2017) and (Vaillancourt et al., 2018).

\subsection{Mexico}

We model the Mexican energy system with GENeSYS-MOD, MUSE, and urbs-MX. Tables B3 and B4 display the percentage of total generation produced with variable renewables and renewables between 2020 and 2050 for each scenario. In GENeSYS - MOD, Ref.0 and Ref.1 are the same because it has no storage capacity present in the first period.

The models calculate electricity consumption differently (i.e., in GENeSYS-MOD and MUSE, the electricity consumption is endogenous, while in urbs- $M X$ exogenous) but they all project an increase in electricity consumption.

MUSE uses the SSP2 to estimate energy demand in each sector. The model then invests in new technologies and operates them depending on the relative ranking of the technological options available according to the sector cost or profit metric, reflecting the dynamic update of prices for fuels. The model also shows a modest increase in power imports from the USA compared to 2015. This increase comes from the relative price variations between both nations.

Despite the use of exogenous demand profile in urbs - MX, this shows compatible electricity demand projections to MUSE. A steeper growth in the demand can be seen in GENeSYS-MOD, driven by the high demand for electric vehicles in the transportation sector and the electrification of high-temperature heating.

Figure 5 shows the results of Ref.0 and Ref. 1 for all three models. In each model, most fossils, except natural gas, decline in the Ref.0 scenario, although with some relevant variations. In 
GENeSYS-MO and urbs - MEX, oil and coal decline quite more rapidly than in MUSE driven by the clean energy mandates. There is also a consistent increase in RES whose uptake rate depends on model-specific cost assumptions and clean energy mandates. RES varies from about $20 \%$ of the electricity demand in 2020 up to $39 \%$ in urbs-MX and $77 \%$ in GENeSYS-MOD. In MUSE, RES uptake remains relatively slower compared to the other two models, and high natural gas uptake dominates the generation mix throughout the simulation period. The main reasons for divergence between the models is the different implementation of clean energy targets across the models. The intertemporal framework used in GENeSYS-MOD and urbs-MX and the forced fossil decommissioning explains a higher and faster RES penetration to meet the clean energy targets. Conversely, the more detailed geographical characterization of Mexico in urbs- $M X$ explains the more conservative uptake in RES compared to GENeSYS-MOD. Finally, the relative variation in the cost projections between wind and solar also affects their relatively different uptake in the three models. In MUSE clean energy mandates can only be approximately simulated with minimum capacity addition; more conservative cost assumptions on VRES lead to less deployment of intermittent renewables compared to other renewable options.

The sensitivity to storage capacity uptake shows little variations from Ref.0. As clean energy targets are imposed (in urbs $-M X$ ), and renewables perform economically better over time (in $M U S E)$, there is growing RES uptake. In Ref.1, the presence of storage tends to favour generation with natural gas because of its competitive production costs.
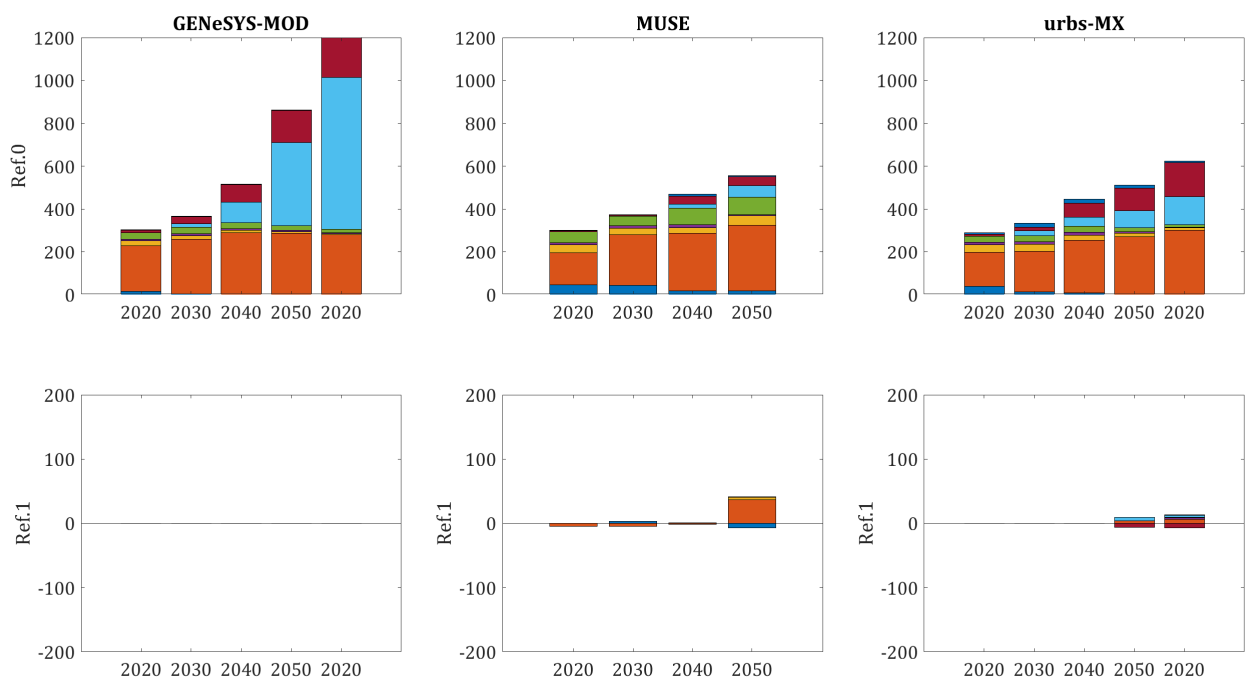

Figure 5: Power Generation through 2050 for Mexico obtained with GENeSYS-MOD, MUSE, and urbs-MX in the reference case (Ref.0) (TWh/y) and the deviation of Ref.1 from Ref.0 (TWh/y). Blue: oil, Orange: natural gas, Yellow: coal, Purple: nuclear, Green: hydropower, Light blue: solar, Dark red: wind, Dark blue: other

Consistent with greater renewable penetration, GENeSY S-MOD shows more significant changes 
between Ref.0 AND Ref.1, where the RES share grows to more than $80 \%$ of the generation. Both the Ren.0 and the Ctax.0 scenarios have variations with the same signs showing an increase in renewables technologies. MUSE shows smaller changes than GENeSYS-MOD. It obtains a higher VRES uptake by substituting natural gas in the Ren.0 scenario with both solar and wind. The imposition of a carbon tax promotes the substitution of fossil (traditional natural gas-fired plants and coal) with abated natural gas plants, rather than renewables. urbs - MX, similar to MUSE, shows an increase in RES, especially VRES, in the Ren.0 scenario. The imposition of a carbon tax favours the substitution of natural gas with wind resources.
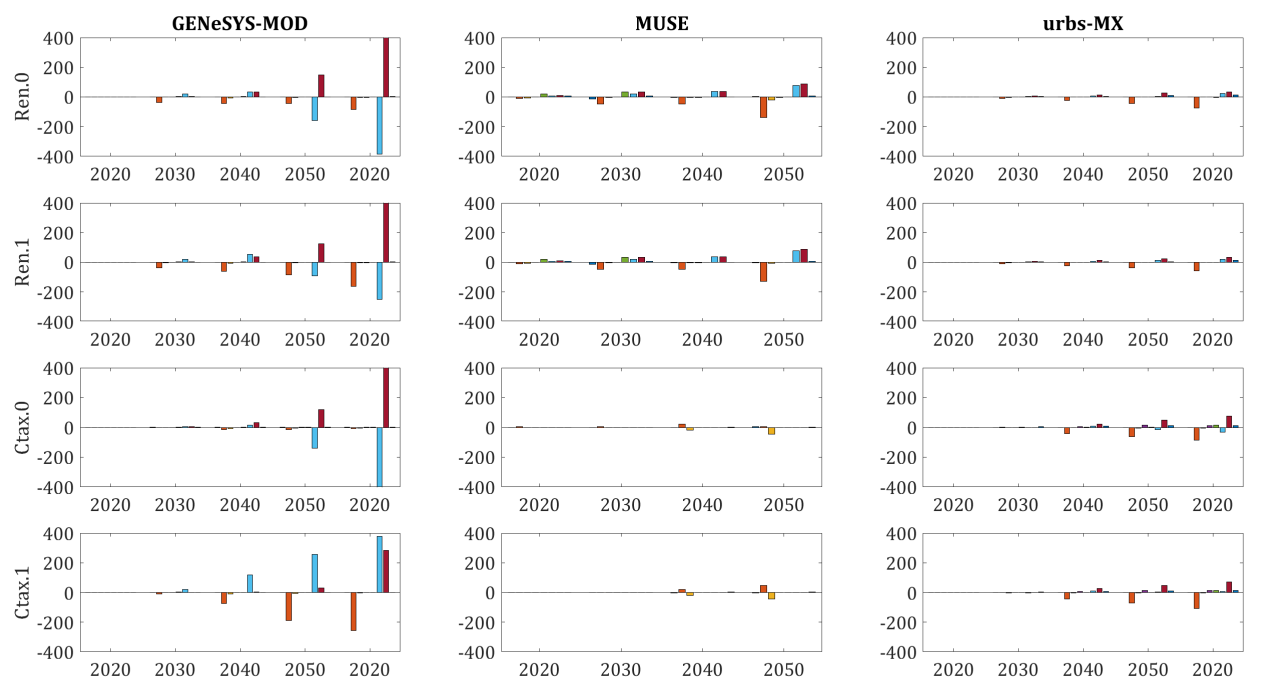

Figure 6: Deviation of power generation through to 2050 for Mexico obtained with GENeSYS-MOD, MUSE, and urbs- $M X$ in the sensitivity cases without storage (Ren.0, Ren.1, Ctax.0, Ctax.1) compared to the corresponding reference Ref.0 (TWh/y). Blue: oil, Orange: natural gas, Yellow: coal, Purple: nuclear, Green: hydropower, Light blue: solar, Dark red: wind, Dark blue: other

\subsubsection{Mexico: sensitivity on storage}

In this section, we show the results in terms of power generation, emissions, and storage capacity for Mexico.

Across all the models (Figure 6), the presence of storage in high renewable mandates scenarios favours the substitution of natural gas with VRES in comparison with Ref.0. The relative proportions between solar and wind uptake depend on the cost assumptions of each model. The models also show different magnitudes in their trends: in GENeSYS-MOD, the scales are higher than in MUSE and urbs $-M X$, mainly driven by a steeper electricity demand increase. In the Ren.0, the presence of storage results in a decrease in VRES (see Table B4), as shown in MUSE and urbs - MEX occurs when natural gas still represents a cheaper option to meet demand. 


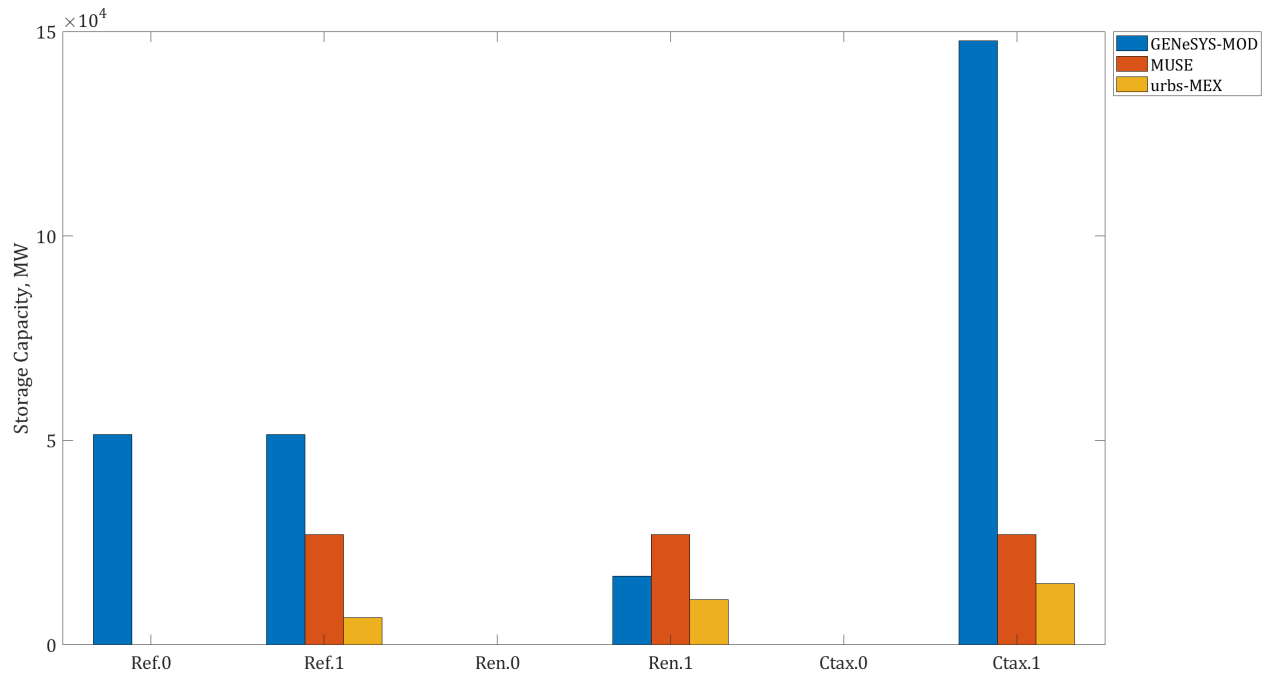

Figure 7: Storage capacity in Mexico - GENeSYS-MOD, MUSE, and urbs - MEX models (MW)

Notes: Battery storage is not represented in $M U S E$ whereas it represents the total storage capacity in $G E N e S Y S-$ $M O D$. In urbs $-M X$ battery storage accounts respectively for $48 \%, 59 \%$, and $65 \%$ of the total installed capacity all the storage capacity is pumped hydro storage.

Similarly, in the carbon tax scenarios, storage promotes VRES when it represents the cheapest generation option and when aligned to clean energy targets, as in GENeSYS-MOD and urbs - MX. Especially in models with high geographical granularity, such as urbs $-M X$, higher renewable production shares is primarily of decentralised type. GENeSYS-MOD shows the highest renewable uptake in line with its largest VRES penetration (see Table B4). In MUSE the high storage costs prevent the model to highly deploy storage. The levels of renewables remain quite unchanged and the system promotes a coal-to-gas substitution.

All the models exhibit the lowest emissions in the Ctax.1 when carbon taxes combine with storage technologies, achieved either through a (as in GENeSYS-MOD and urbs - MEX) or decommissioning of unabated coal technologies (as in MUSE).

\subsection{USA}

In this section, we show the results of MUSE regarding the USA energy system. Driven by greater natural gas efficiency, the Ref.0 scenario, in line with Canada and Mexico, shows a technology mix with a growing reliance on natural gas (Figure 9). Oil and coal decline, reflecting inefficiencies in the technologies compared to natural gas.

The USA increases the uptake of renewables throughout the optimisation period, particularly after 2030, when the model envisages a sharp reduction in renewables' CAPEX. Tables B6 and B5 show the share of VRES and RES in the power production matrix of the United States. Moreover, 


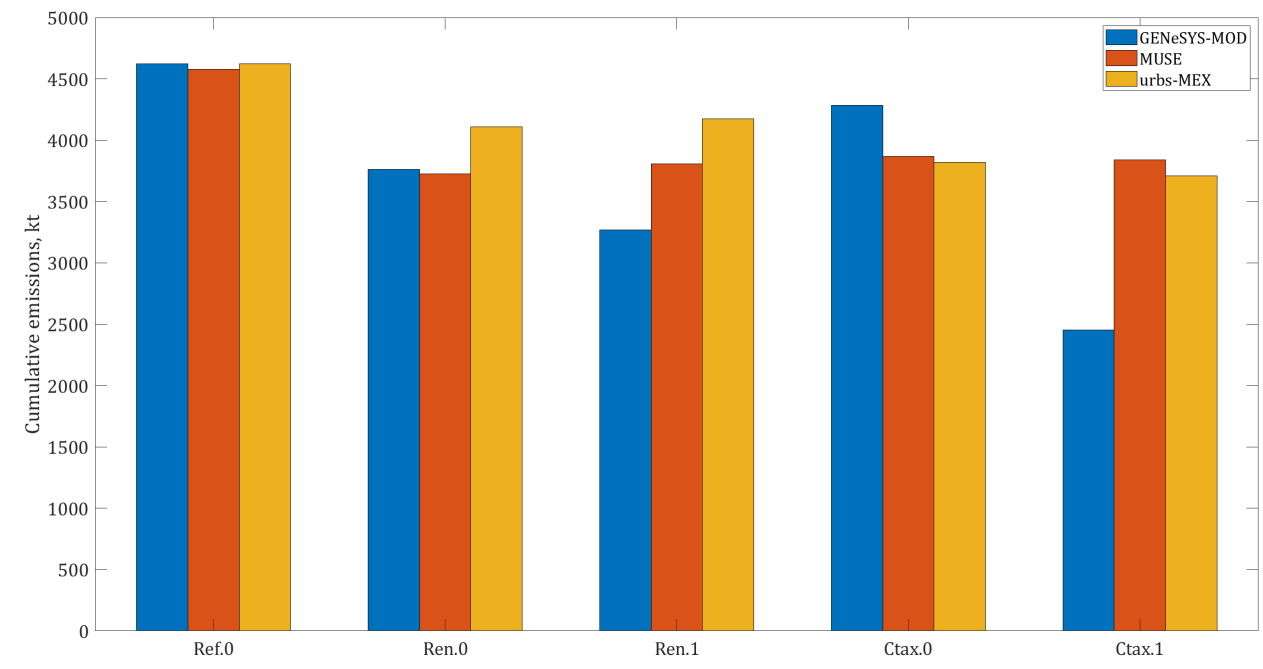

Figure 8: Cumulative emissions in Mexico between 2020 and $2050-$ GENeSYS-MOD, MUSE, and urbs - MEX (kt of $\mathrm{CO}_{2}$ )

the model also finds a higher penetration of solar vs. wind facilities. Nuclear tends to decline in generation over time due to the relative technological costs. In the presence of storage, renewables substitute natural gas generation because of more competitive generation costs. However, a carbon tax imposition in $M U S E$, shows as in Canada and Mexico, a preference for abated technologies rather than renewables.
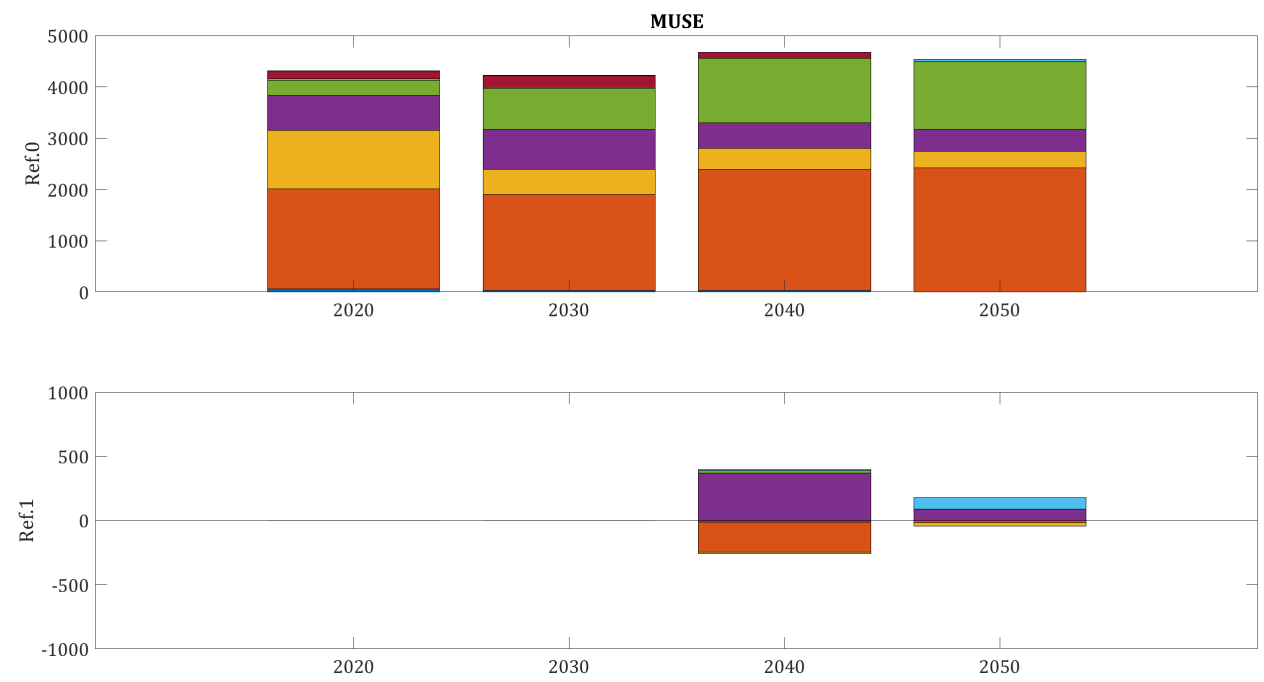

Figure 9: Power generation through 2050 for USA obtained with MUSE in the reference case (Ref.0) (TWh/y) and the deviation of Ref.1 from Ref.0 (TWh/y). Blue: oil, Orange: natural gas, Yellow: coal, Purple: nuclear, Green: hydropower, Light blue: solar, Dark red: wind, Dark blue: other 

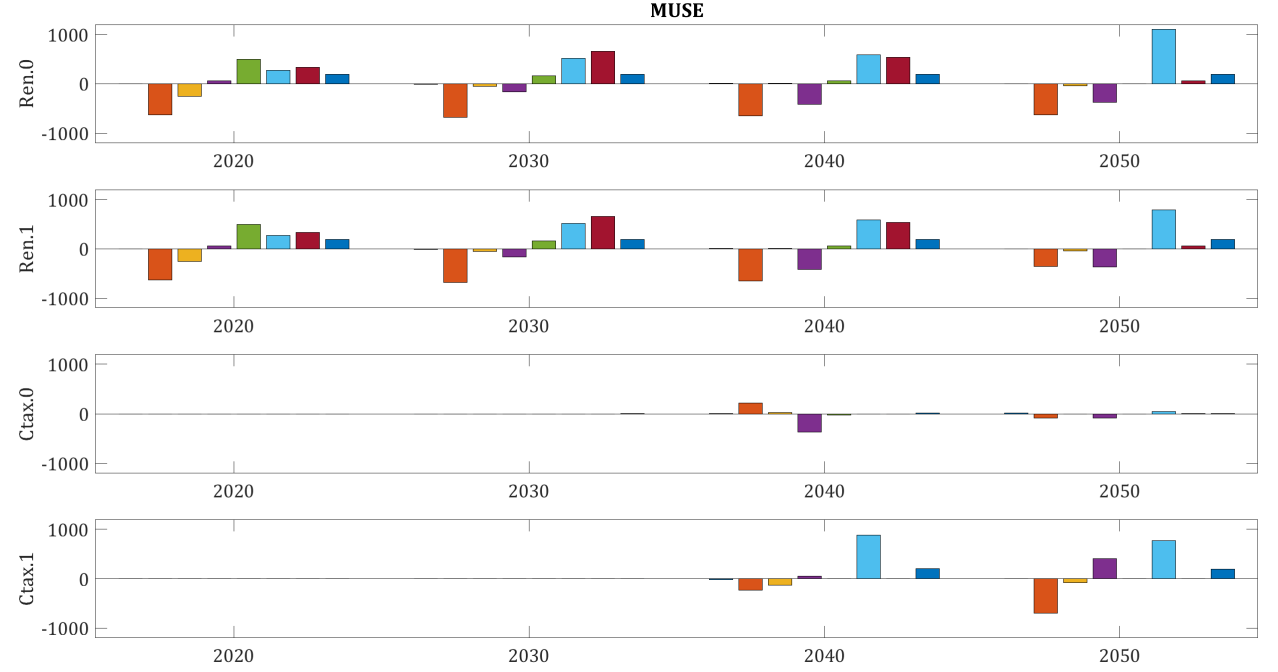

Figure 10: Deviation in power generation through to 2050 for USA obtained with $M U S E$ : variation from Ref.0 (TWh/y). Blue: oil, Orange: natural gas, Yellow: coal, Purple: nuclear, Green: hydropower, Light blue: solar, Dark red: wind, Dark blue: other

\subsubsection{Other cases: high RES and carbon tax in USA}

In scenario Ren.1, storage reduces the share of VRES compared with Ren.0 because it promotes electricity production with the cheapest energy source (natural gas). The highest storage uptake happens in the Ctax.1 scenario, favouring solar to natural gas power facilities. Overall, in the Ctax.1 scenario, a more significant fraction of renewables and the decommissioning of natural gas allows reaching the highest emissions reduction compared to the other cases (see Figure 11). 

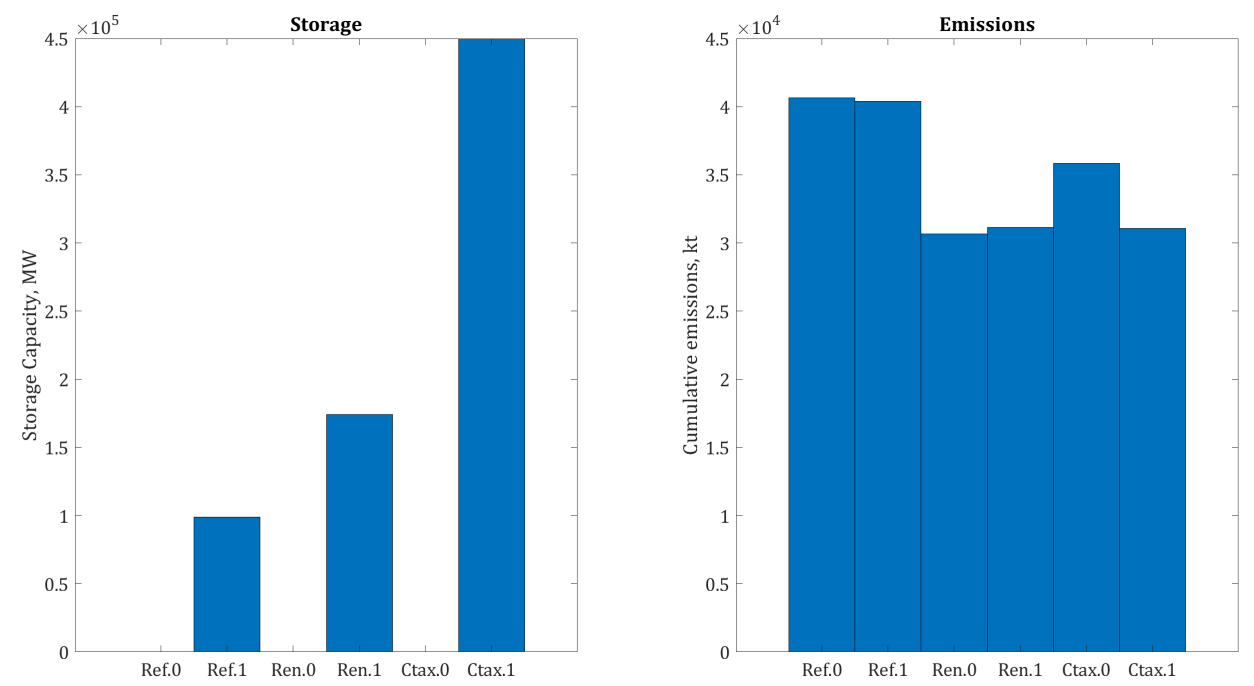

Figure 11: Storage capacity and cumulative emissions between 2020 and 2050 in USA

Notes: Battery storage accounts for $33 \%$ of the total installed capacity in the Ctax.1 scenario. 


\section{Discussion}

The model inter-comparison shows a positive correlation between storage and VRES as storage is installed even at VRES lower than $10 \%$ of the total generation (Figure 12). The ranges of VRES uptake and storage capacities vary across models reflecting differences in costs and resource availability.

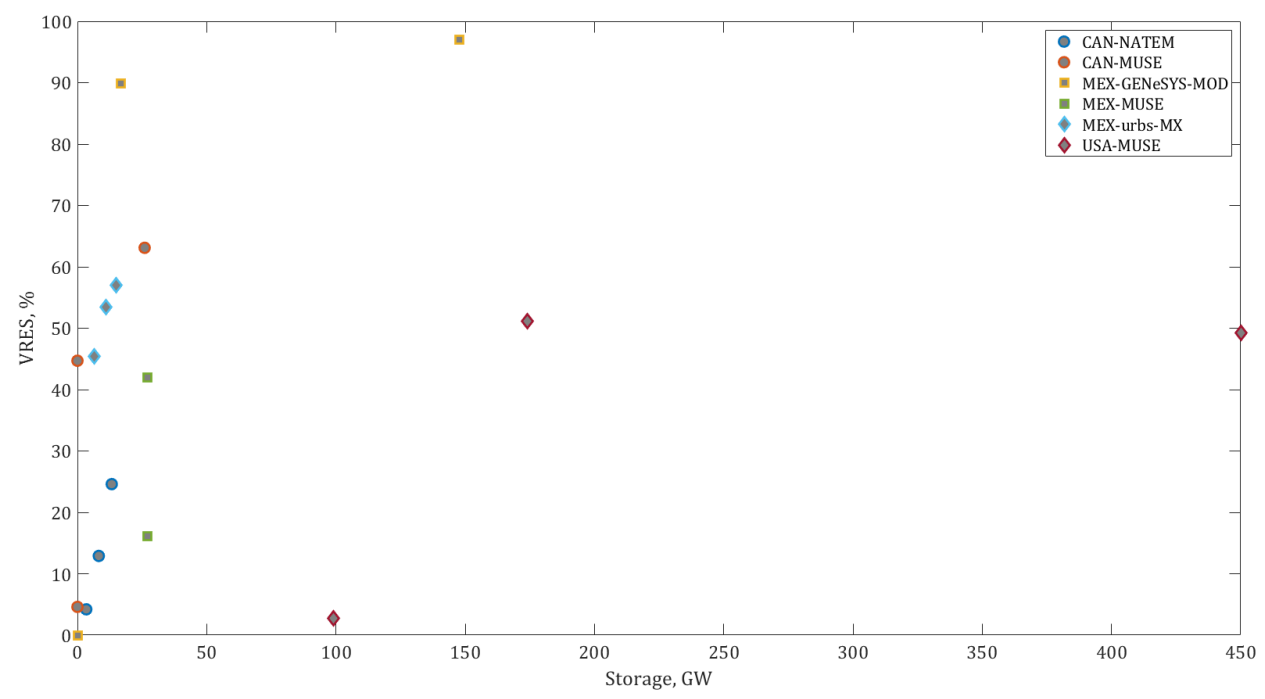

Figure 12: Variable renewables (VRES) versus storage capacity

The uncertainty in the energy futures can be explained as follows:

- Model behaviour. All models except MUSE are based on inter-temporal optimisation. Because of the perfect foresight, they optimise the energy system based on the knowledge of the future values resource availability, capital costs, variable costs, fixed costs, and residual capacity among others. In MUSE the presence of limited foresight tends to produce a slower and more expensive transition as the dynamic development of certain cost patterns, such as the decrease in renewable costs or storage after 2030 cannot be anticipated. In this way, the transition towards renewables and storage is delayed in MUSE compared to other models. One of the main limitations we found across models was the detailed in the modelling approach lacking a detailed unit commitment modelling, which might cause underestimations in the amount of storage needed.

- Cost parametrisation. One of the most important factors affecting the results appears to be the assumptions on the initial costs of storage. High cost values, tend to reduce the uptake of storage. In this way we can explain the lower levels of storage in MUSE compared to other models; over time, there is a cost dynamic between renewables and storage as both 
are decreasing in their costs. More sensitivity analyses is required to better understand the impacts of future cost assumptions on the optimal electricity generation mix.

- Geographical granularity. Models with higher granularity offer a more detailed representation of the the energy systems in any jurisdictions. This is reflected in cost trajectories of future hydro dam projects, of solar and wind projects, and storage options which vary by jurisdiction/region. The higher granularity leads to a representation of the energy system where constraints due to local electricity demand, local capacity factors, and local policy constraints generally leads to higher investments in storage capacity keeping the level of VRES constant. This can be observed comparing the results for Canada moving from NATEM (high resolution) to $M U S E$ (low resolution). In Mexico, while urbs $-M X$ shows higher storage capacities even at lower renewables levels compared to GENeSYS - MOD. In MUSE the level of VRES always remain quite low, because of the competition with other sources; therefore a direct correlation between storage and renewables is not observed.

- Temporal granularity. As the number of timeslices increases, we obtain a more precise allocation of the renewables availability to a specific time. The smallest sub-year slice we can model, is the hour (in urbs $-M X$ ). In Mexico, we can see for example that at comparable levels of renewables but greater than $50 \%$, highly resolved time models such as urbs - $M X$ relies more on storage.

\section{Conclusion and Policy Implications}

The role of electricity storage in the renewable transition is essential for achieving the decarbonization of the power system. In this paper, we present a model comparison approach for four models (GENeSYS-MOD, MUSE, NATEM, and urbs-MX). We use each model to simulate scenarios of long-term storage potentials under harmonised assumptions of the power sector development as characterised by high variable renewable electricity generation in North America.

A model inter-comparison approach allows us to examine similarities in energy systems when different modeling teams with different underlying assumptions analyse the deployment of selected technologies in presence of specific policies. In this study, we concentrate on storage technologies and we assess the effect of this technology deployment on the energy system of North America considering a high uptake of renewables. We opt out from a full harmonisation across models in order to produce an analysis where the implications of techno-economic differences are embedded in the scenarios. Projections of costs are widely uncertain as subjected to a variety of factors, such as policies and stakeholders' interests, which cannot be modelled without making strong or unlikely assumptions. Assuming a unique trajectory for costs, specifically in the case of storage technologies, would have 
been arbitrary and could have narrowed the analysis rather than offering a more comprehensive view of the technology potentials in interplay with the variable renewables uptake. The harmonisation was limited to historical emission in the base year (2015), to the qualitative mapping of key technologies in the power sector, and to the representation of high impact policies. This allow us to claim that the overall trend in the outcomes does not depend on the data, specifically on the techno-economic parametrisation.

Across all models, the regional storage technology cost reduction is one of the most important factors affecting the uptake of storage technologies. Thus, it is important for governments to keep subsidizing the deployment of the technology. However, cost reduction of storage on its own does not imply an uptake of the technology, unless it is coupled with high renewable mandates, especially variable renewable sources, whose cost also needs to be reduced with time. In all the three regions, storage is favoured by decentralised power generation; this was especially clear in models with higher regional granularity.

Results also show that the imposition of high renewable energy mandates (obtainable by setting minimum shares of renewables or by reducing the renewable technologies costs) has the most substantial influence on the storage uptake. The imposition of a carbon tax also favours the uptake of storage when the availability of intermittent renewables is at lower cost than the alternative low-carbon options.

From the modelling perspective, electricity storage modelling would improve if coupled with a detailed modelling of the power sector especially considering details of the unit commitment problem. Due to the complexities of integrated assessment models, one way to to overcome this could come from soft-linking them with detailed power sector models. In addition to the simplified unit commitment modelling, resource availability, and power sector technologies sub-hour dynamics, more research to improve integrated assessment modelling would be needed in terms of modelling renewable curtailment and interconnectors.

\section{Acknowledgements}

The authors acknowledge funding from the Sustainable Gas Institute. Funding for the Sustainable Gas Institute is gratefully received from Royal Dutch Shell, Enagas SA, and the Newton/NERC/FAPESP Sustainable Gas Futures project NE/N018656/1. Olivier Bahn and Kathleen Vaillancourt also acknowledge financial support from the e3 Hub at HEC Montréal. Note that the funding bodies were not involved in the design, implementation, or reporting of this study. 
10. Symbols

$B E C C S$ biomass-fired power combined with carbon capture and storage

CCS carbon capture and storage

GDP gross domestic product

GHG greenhouse gas

IEA International Energy Agency

RES renewable energy sources

$V R E S \quad$ variable renewable energy sources 


\section{Appendix A}

Model description

GENeSYS-MOD. (Global Energy System Model) GENeSYS-MOD is an optimisation model based on the Open-Source Energy Modeling System (OSeMOSYS) framework, developed by the Royal Institute of Technology in Stockholm, Sweden (Howells et al., 2011). Loffler et al. (2017) extended OSeMOSYS to GENeSYS-MOD by including new functionalities, such as a modal split for transportation, an improved trade system, and an enhanced focus on environmental budgets. Lawrenz et al. (2018) further enhanced GENeSYS-MOD in their case study on transition pathways of the Indian energy system, while (Burandt et al., 2018) introduced the second model version, with improvements to storages, time slices, and performance optimisation. Specifically, GENeSYS$M O D$ splits the energy market into different sectors, technologies, and processes. It endogenously optimises the power, transportation and heating sectors, while accounting for sector coupling; and from macroeconomic models because of its high level of technical detail. The key advantage of GENeSYS-MOD is the open-source approach of code and data and that the model is freely available. The capacity of GENeSYS-MOD to subdivide the energy system into sectors, technologies, and regions, its ability to account for sector coupling, and its high degree of technological features are necessary characteristics of a model attempting to understand the consequences of exogenous variations in energy and climate policies on each supply option, energy sector, and modelled region. Overall, numerical models allow analysing a great variety of problems across several sectors and sciences. Techno-economic models have shown the ability to analyse costs and effects of a transition toward low-carbon technologies in national energy and power mixes. The power sector is the one sector that historically, and recently, has received the most attention.

GENeSYS-MOD optimises the energy system by using a system of linear equations as constraints and inputs to minimize the aggregated cost of the energy system, while securing the supply of energy in a specific region. The model objective function is a total cost minimisation which also includes the salvage value of a technology. The model also contains additional constraints determining the proper functionality of elements, such as energy balances, emission limits, or renewable integration. As a techno-economic numerical model, GENeSYS-MOD is subject to the relevant limitations of these kind of models. It requires exogenous inputs on forecast demands, costs, and technological paths. Regarding the demand for transportation, power, and heating, these come from third-party sources, such as the national program for the development of the energy system (PRODESEN), or are imputed with the use of GDP and population estimates. Furthermore, because of the integrated modelling approach for the entire period between 2020 and 2050, it is only possible to include a given number of time slices per year, sixteen-time slices, including four different seasons (spring, summer, autumn, winter) and four intra-day cuts (morning, peak, evening, night). These time slices intend 
to account for peak demand periods in summer and afternoons.

MUSE. MUSE, the ModUlar energy systems Simulation Environment, is a global model of the energy systems which simulates the energy systems transitions over long time horizons, using a partial equilibrium on the energy system. The model simulates the whole energy system, including demand, transformation/conversion, and supply sectors. The approach to the sector modelling is modular where each sector of the energy system is simulated by an individual module, thus guaranteeing that the modelling is specific to that sector. The sector interacts with the rest of the energy system though a partial equilibrium framework, offered by a market equilibrium algorithm which balances each energy commodity supply and demand (Giarola et al., 2019). The market works using a dynamic recursive algorithm to match supply and demand in an imperfect foresight temporal simulation approach.

The model uses a bottom-up approach to the technology characterisation which enables a high degree of detail of the technical and environmental description (Garcia et al., 2019). An agent-based modelling approach is applied to the modelling of the key players in each energy sector (Sachs et al., 2019).

The power sector in MUSE considers all the conventional thermal technologies based on coal, oil, gas, biomass, renewables, hydro-pump storage and lithium-ion battery storage. The storage runs before dispatchable technologies to flatten the residual demand and the energy from positive part to serve the negative part considering the conversion losses and reducing the total system cost avoiding additional and higher investment on other technologies. The simulation of new investments aims at reducing the marginal costs of the investments.

The intermittancy of the electric output from renewables is described through aggregated capacity factors obtained from a detailed spatially explicit analysis which integrates the methodology described in (Bosch et al., 2017).

The electricity demand is an aggregation of the sectors demand endogenously calculated following seasonal (three seasons) and diurnal load shapes for a total of 30 time slices. Specifically, three seasons (winter, spring-autumn, summer), four slices in a day (night, morning, afternoon, evening time slices), and two additional demand peaks during weekdays are modelled.

NATEM. NATEM (Vaillancourt et al., 2017) is an optimisation model that belongs to the TIMES family of models supported by the Energy Technology Systems Analysis Program (ETSAP) of the International Energy Agency (Loulou and Labriet, 2008). TIMES models in general are technology-rich and rely on the concept of a Reference Energy System that describes energy value chains from primary energy (e.g., fossil fuel reserves, biomass feedstock, renewable potential, etc.) to useful energy (e.g., demand for transportation, cement, space heating, etc.). As such, NATEM 
describes the entire integrated energy system of the 13 Canadian provinces and territories while capturing all intergovernmental and international flows of energy commodities and materials. The model is driven by 70 end-use demands for energy services in five end-use sectors (agriculture, commercial, residential, industrial, transport) which are specified exogenously over the 2050 horizon. At each point of the energy system, numerous technologies are competing, for example, to satisfy a demand for an energy service or the supply an energy commodity. NATEM uses dynamic linear programming with the objective to minimize the overall system cost. It compute a partial equilibrium of the energy system. The main outputs of the model (decision variables) include future technology investments with their annual activity levels, optimal energy trade movements, as well as marginal prices for each energy, material and demand commodity. An important assumption about the decision process of economic actors is the perfect foresight approach, where actors can anticipate future events while making optimal decisions today. The optimisation is done once over the whole time horizon through 10 variable length time periods and 16 annual time slice (four seasons and four intraday periods). The model accounts for direct GHG emission coefficients from fuel combustion as well as coefficients for fugitive emissions and GHG emissions from non-energy sectors (industrial processes, agriculture and waste). This enables NATEM to capture substitution of energy forms and to comply with GHG reduction or renewable penetration targets (constraints). For the energy supply side, NATEM captures all sectors including electricity and heat generation. Other supply sectors includes fossil fuels extraction, upgrading and transport, uranium extraction and transport, petroleum refining, bioenergy production, natural gas liquefaction and exports, hydrogen supply chain, etc. The database depicts individually all existing power plant units, in addition to units already planned for construction or refurbishment in future years. For replacement of existing capacity at the end of lifetime or the addition of new capacity to meet the additional demand for electricity a repository includes several types of thermal, nuclear, biomass and renewable power plants. Hydro potential is represented through three-step supply curves with increasing costs for developing the remaining hydraulic resource. Resource intermittancy is captured at the 16 time slice level though an aggregation of hourly data. The new technology repository also includes pumped hydro options as a way to store electricity between seasons. Capture options are available for coal, gas and biomass power plants and sequestration options for enhanced oil recovery, oil \& gas fields and saline aquifers. In addition, the model database contains a distributed electricity option, currently limited to grid-connected solar photovoltaic panels for residential and commercial buildings, as well as battery storage options. Finally, major transmission interconnections between Canadian jurisdictions and to the United States are modelled as specific infrastructure technologies with installed capacity and capacity factors, but the distribution system is modelled in a more aggregated and generic manner. The model used for this study did not include an optimal dispatch module. 
urbs - MX - urbs model for Mexico. urbs - MX is a nine-region model of the Mexican power system based on urbs, an open-source linear optimisation modeling framework for capacity expansion and unit commitment analyses (Dorfner J, Schönleber K, Dorfner M, Candas S, Müller S, Odersky L, Özsahin Y, et al., 2018). It minimizes the annual system costs which comprise all investment costs by their annualized depreciation as well as the operational and environmental costs. As a result, the least-cost portfolio of generators, storage and transmission that meet the exogenous electricity demand at every hour of the modelled year under capacity and environmental constraints is deterministically calculated. Furthermore, it allows the integration of multiple input and output commodities resulting in detailed representations of the energy conversion processes. A high temporal resolution ( $8760 \mathrm{~h}$ per year) is used to ensure the chronological tracking of storage (Frew and Jacobson, 2016). urbs - MX considers 17 power generation technologies and two storage options. Conventional generation includes thermal power plants based on coal, fuel oil and natural gas; natural gas-fired cogeneration; combined cycle gas turbines; nuclear; and gas turbines and internal combustion engines as peak technologies with natural gas, fuel oil and diesel as fuels. Renewable generation includes bioenergy, geothermal energy, hydropower with reservoir, run-off-river hydropower, wind power and photovoltaics. Hydro-pump storage and lithium-ion battery are the two considered storage technologies. Further details are found in (Molar-Cruz et al., 2018). Dispatchable generating technologies are technically characterized by their maximum allowed hourly power gradient relative to the power throughput capacity, minimum load fraction, annual availability and full- and partialload efficiencies. Intermittent renewables are modelled using regional time series of capacity factors derived from historical weather data. Up to three sub-regions are used to spatially characterize the renewable potential of large regions with heterogeneous conditions. Storage technologies store one commodity and are sized in terms of energy capacity and charging/discharging power capacity. Energy and power capacities are expanded independently, however, for batteries, a linear dependence between them is integrated. As explained in (Dorfner, Johannes, 2016), the storage content at one time step is the difference of incoming and outgoing flows, added to the storage content in the previous time step and scaled by charging, discharging and self-discharge efficiencies.

\section{Appendix B}

Additional tables 
Table B1: Share of electricity generation [\%] Renewable sources

\begin{tabular}{lccccc}
\hline RES share & Scenario & 2020 & 2030 & 2040 & 2050 \\
\hline NATEM & Ref.0 & 66.5 & 65.3 & 60.6 & 55.1 \\
MUSE & Ref.0 & 52.4 & 42.8 & 41 & 45.5 \\
NATEM & Ref.1 & 66.1 & 65.1 & 60.7 & 55.4 \\
MUSE & Ref.1 & 52.4 & 42.8 & 41 & 45.6 \\
NATEM & Ren.0 & 66.5 & 65.3 & 60.7 & 67.2 \\
MUSE & Ren.0 & 58.2 & 61.8 & 63.4 & 62.8 \\
NATEM & Ren.1 & 66.1 & 65.1 & 61.3 & 64.9 \\
MUSE & Ren.1 & 58.2 & 61.8 & 63.4 & 63.1 \\
NATEM & Ctax.0 & 66.9 & 66.5 & 64.8 & 74.1 \\
MUSE & Ctax.0 & 52.4 & 42.8 & 41 & 45.1 \\
NATEM & Ctax.1 & 66.8 & 66 & 72.1 & 78.5 \\
MUSE & Ctax.1 & 52.4 & 42.8 & 40.8 & 44.7 \\
\hline
\end{tabular}

Table B3: Share of electricity generation [\%] Renewable sources in Mexico

\begin{tabular}{lccccc}
\hline RES share & Scenario & 2020 & 2030 & 2040 & 2050 \\
\hline GENeSYS & Ref.0 & 21.9 & 39.9 & 65 & 76.7 \\
MUSE & Ref.0 & 18.3 & 13.6 & 28.6 & 31.8 \\
urbs & Ref.0 & 20.2 & 30.6 & 39.8 & 48.4 \\
GENeSYS & Ref.1 & 21.9 & 39.9 & 65 & 76.7 \\
MUSE & Ref.1 & 18.6 & 13.7 & 28.7 & 29.9 \\
urbs & Ref.1 & 20.2 & 30.6 & 39.4 & 47.4 \\
GENeSYS & Ren.0 & 30.4 & 51.5 & 68.2 & 85.2 \\
MUSE & Ren.0 & 28.4 & 34.3 & 42.5 & 56.7 \\
urbs & Ren.0 & 23.2 & 35.3 & 45.3 & 56.8 \\
GENeSYS & Ren.1 & 30.5 & 55.1 & 73.4 & 91.2 \\
MUSE & Ren.1 & 28.4 & 34.3 & 42.5 & 55.2 \\
urbs & Ren.1 & 23.2 & 35.2 & 46.4 & 55.2 \\
GENeSYS & Ctax.0 & 24.1 & 47.1 & 65.6 & 80.4 \\
MUSE & Ctax.0 & 18.3 & 13.6 & 28.6 & 31.8 \\
urbs & Ctax.0 & 19.3 & 37.9 & 47 & 57.4 \\
GENeSYS & Ctax.1 & 27.5 & 59.2 & 88.7 & 98.1 \\
MUSE & Ctax.1 & 18.6 & 13.7 & 28.7 & 29.9 \\
urbs & Ctax.1 & 19.3 & 38.7 & 49.3 & 61.4 \\
\hline
\end{tabular}

Table B5: Share of electricity generation [\%] Renewable sources in the USA

\begin{tabular}{lccccc}
\hline Model & Scenario & 2020 & 2030 & 2040 & 2050 \\
\hline MUSE & 1.1 & 11.1 & 27.9 & 32.4 & 29.8 \\
MUSE & 1.2 & 11.1 & 28.1 & 33.3 & 32.2 \\
MUSE & 2.1 & 37.9 & 64.4 & 61.5 & 58 \\
MUSE & 2.2 & 37.9 & 64.4 & 61.5 & 51.1 \\
MUSE & 3.1 & 11.1 & 28.1 & 32.7 & 33.4 \\
MUSE & 3.2 & 11.1 & 28.1 & 54.3 & 49.2 \\
\hline
\end{tabular}

Table B2: Share of electricity generation [\%] Variable Renewables (solar, wind)

\begin{tabular}{lccccc}
\hline VRES share & Scenario & 2020 & 2030 & 2040 & 2050 \\
\hline NATEM & Ref.0 & 5.3 & 0.4 & 4.8 & 3.4 \\
MUSE & Ref.0 & 4.3 & 0.4 & 5.2 & 4.6 \\
NATEM & Ref.1 & 5.5 & 0.6 & 5.2 & 4.2 \\
MUSE & Ref.1 & 4.3 & 0.4 & 5.2 & 4.6 \\
NATEM & Ren.0 & 5.3 & 0.4 & 4.8 & 13.7 \\
MUSE & Ren.0 & 6.8 & 3.6 & 18.7 & 20.8 \\
NATEM & Ren.1 & 5.5 & 0.6 & 5.6 & 12.9 \\
MUSE & Ren.1 & 6.8 & 3.6 & 18.7 & 20.9 \\
NATEM & Ctax.0 & 5.4 & 0.4 & 7.2 & 19.9 \\
MUSE & Ctax.0 & 4.3 & 0.4 & 5.2 & 4.5 \\
NATEM & Ctax.1 & 5.5 & 0.6 & 14.2 & 24.6 \\
MUSE & Ctax.1 & 4.3 & 0.4 & 5.2 & 4.5 \\
\hline
\end{tabular}

Table B4: Share of electricity generation [\%] Variable Renewables (solar, wind) in Mexico

\begin{tabular}{lccccc}
\hline VRES share & Scenario & 2020 & 2030 & 2040 & 2050 \\
\hline GENeSYS & Ref.0 & 13.2 & 18.5 & 62.5 & 75.3 \\
MUSE & Ref.0 & 1.8 & 0 & 11.9 & 17.1 \\
urbs & Ref.0 & 11.6 & 9.5 & 36.1 & 46.5 \\
GENeSYS & Ref.1 & 13.2 & 18.5 & 62.5 & 75.3 \\
MUSE & Ref.1 & 1.9 & 0 & 11.9 & 16.1 \\
urbs & Ref.1 & 11.6 & 9.5 & 35.6 & 45.4 \\
GENeSYS & Ren.0 & 20.5 & 24 & 65.3 & 83.9 \\
MUSE & Ren.0 & 6.4 & 4.9 & 26.3 & 43.1 \\
urbs & Ren.0 & 14.7 & 11.1 & 41.8 & 55.2 \\
GENeSYS & Ren.1 & 20.6 & 27.6 & 70.5 & 89.9 \\
MUSE & Ren.1 & 6.4 & 4.9 & 26.3 & 42 \\
urbs & Ren.1 & 14.7 & 11.4 & 42.8 & 53.4 \\
GENeSYS & Ctax.0 & 14.9 & 20.3 & 62.8 & 79.1 \\
MUSE & Ctax.0 & 1.8 & 0 & 11.9 & 17.1 \\
urbs & Ctax.0 & 10.8 & 11.7 & 43 & 52.8 \\
GENeSYS & Ctax.1 & 18.4 & 38.4 & 86.3 & 97 \\
MUSE & Ctax.1 & 1.9 & 0 & 11.9 & 16.1 \\
urbs & Ctax.1 & 10.8 & 11.7 & 45.4 & 57 \\
\hline
\end{tabular}

Table B6: Share of electricity generation [\%] Variable Renewables (solar, wind) in the USA

\begin{tabular}{cccccc}
\hline Model & Scenario & 2020 & 2030 & 2040 & 2050 \\
\hline MUSE & 1.1 & 3.7 & 0.5 & 2.4 & 0.8 \\
MUSE & 1.2 & 3.7 & 0.5 & 2.5 & 2.7 \\
MUSE & 2.1 & 16.1 & 11.1 & 24.1 & 25.9 \\
MUSE & 2.2 & 16.1 & 11.1 & 24.1 & 19.7 \\
MUSE & 3.1 & 3.7 & 0.5 & 2.4 & 4 \\
MUSE & 3.2 & 3.7 & 0.5 & 18 & 17.1 \\
\hline
\end{tabular}




\section{Bigliography}

\section{References}

Arpa-e DoE. Duration Addition to electricitY Storages. Technical Report; Electric Vehicle Transportation Center; 2020. URL: https://arpa-e.energy.gov/technologies/programs/days.

Benato A, Stoppato A. Pumped Thermal Electricity Storage: A technology overview. Thermal Science and Engineering Progress 2018;6:301-15. URL: https://www.sciencedirect.com/ science/article/pii/S2451904917303700. doi:10.1016/J .TSEP. 2018.01.017.

Bogdanov D, Farfan J, Sadovskaia K, Aghahosseini A, Child M, Gulagi A, Oyewo AS, de Souza Noel Simas Barbosa L, Breyer C. Radical transformation pathway towards sustainable electricity via evolutionary steps. Nature Communications 2019;10(1):1077. URL: https://doi.org/10. 1038/s41467-019-08855-1. doi:10.1038/s41467-019-08855-1.

Bosch J, Staffell I, Hawkes AD. Temporally-explicit and spatially-resolved global onshore wind energy potentials. Energy 2017;131:207-17. URL: https://www.sciencedirect.com/science/ article/pii/S0360544217308095. doi:10.1016/J.ENERGY.2017.05.052.

Burandt T, Löffler K, Hainsch K. GENeSYS-MOD v2.0 - Enhancing the Global Energy System Model: Model Improvements, Framework Changes, and European Data Set. Technical Report; DIW Berlin; 2018.

Burtin A, Silva V. Technical and economic analysis of the European electricity system with $60 \%$ RES. Technical Report; EDF; 2015.

Castagneto Gissey G, Subkhankulova D, Dodds PE, Barrett M. Value of energy storage aggregation to the electricity system. Energy Policy 2019;128:685-96. URL: https://www. sciencedirect. com/science/article/pii/S0301421519300655. doi:10.1016/J .ENPOL . 2019.01.037.

Cochran J, Danholm P, Speer B, Miller M. Grid Integration and the Carrying Capacity of the U . S . Grid to Incorporate Variable Renewable Energy. Technical Report April; National Renewable Energy Laboratory; 2015.

Cochran J, Miller M, Zinaman O, Milligan M, Arent D, Palmintier Bea. Flexibility in 21st Century Power Systems. Technical Report; 21st Power Partnership; 2014. URL: https://www.nrel.gov/ docs/fy14osti/61721.pdf.

Cole W, Frazier AW. Cost Projections for Utility- Scale Battery Storage Cost Projections for UtilityScale Battery Storage. Technical Report; NREL - National Renewable Energy Laboratory; 2019. URL: https://www.nrel.gov/docs/fy19osti/73222.pdf. 
Cole W, Frew B, Mai T, Bistline J, Blanford G, Young D, Marcy C, Namovicz C, Edelman R, Meroney B, Sims R, Donohoo-vallett P, Cole W, Frew B, Mai T, Bistline J, Blanford G, Young D, Edelman R, Meroney B, Sims R, Donohoo-vallett P. Variable Renewable Energy in Long-Term Planning Models : A Multi-Model Perspective Variable Renewable Energy in Long-term Planning Models : A Multi-model Perspective. Technical Report; NREL - National Renewable Energy Laboratory; 2017.

Crampes C, Trochet JM. Economics of stationary electricity storage with various charge and discharge durations. Journal of Energy Storage 2019;doi:10.1016/j .est.2019.04.020.

Dellink R, Chateau J, Lanzi E, Magné B. Long-term economic growth projections in the Shared Socioeconomic Pathways. Global Environmental Change 2017;42:20014. URL: http://www.sciencedirect.com/science/article/pii/S0959378015000837. doi:https ://doi.org/10.1016/j.gloenvcha.2015.06.004.

Després J, Mima S, Kitous A, Criqui P, Hadjsaid N, Noirot I. Storage as a flexibility option in power systems with high shares of variable renewable energy sources: a POLES-based analysis. Energy Economics 2017;64:638-50. URL: https://www.sciencedirect.com/science/article/ pii/S0140988316300445. doi:10.1016/j.eneco.2016.03.006.

Dorfner J, Schönleber K, Dorfner M, Candas S, Müller S, Odersky L, Özsahin Y, et al. . urbs: A linear optimisation model for distributed energy systems. v0.7.3. 2018. doi:https://doi.org/ $10.5281 /$ zenodo. 1228851 .

Dorfner, Johannes . Open source modelling and optimisation of energy infrastructure at urban scale. Ph.D. thesis; Technical University of Munich; 2016.

ECCC . Canada's Mid-Century Long term Low Greenhouse Gas Development Strategy. Canada's Submission to the United Nations Framework Convention on Climate Change (UNFCCC). Technical Report; Environment and Climate Change Canada; 2016.

Elshurafa AM. The value of storage in electricity generation: A qualitative and quantitative review. Journal of Energy Storage 2020;32(September):101872. URL: https ://doi . org/10.1016/j . est . 2020.101872. doi:10.1016/j. est. 2020.101872 .

Frew BA, Jacobson MZ. Temporal and spatial tradeoffs in power system modeling with assumptions about storage: An application of the POWER model. Energy 2016;117:198-213. URL: https:// WWW.sciencedirect.com/science/article/pii/S0360544216315110. doi:10.1016/J.ENERGY. 2016 . 10 . 074. 
Fripp M, Dunn MD. Intermodel Comparison Between Switch 2. 0 and GE MAPS : Evaluating a New Tool for Integrated Modeling of Electric Vehicles and High-Renewable Power Systems. Technical Report; Electric Vehicle Transportation Center; 2018.

Fyke A. The Fall and Rise of Gravity Storage Technologies. Joule 2019;3(3):625-30. URL: https://www.sciencedirect.com/science/article/pii/S2542435119300418. doi:10. 1016/J . JOULE. 2019.01.012.

Garcia KI, Giarola S, Hawkes A. A novel energy systems model to explore the role of land use and reforestation in achieving carbon mitigation targets: A brazil case study. Journal of Cleaner Production 2019;232:796-821. URL: http://dx.doi.org/10.1016/j.jclepro.2019.05.345. doi:10.1016/j.jclepro.2019.05.345.

Gardner P, Jones F, Rowe M, Nouri A, van de Vegte H, Breisig V, Linden C, Pütz T. WORLD ENERGY COUNCIL World Energy Resources. https://wwwworldenergyorg/wpcontent/uploads/2016/03/Resources-E-storage-report-20160204pdf 2016;.

Giarola S, Crow D, Hawkes A. Simulating the carbon price trajectory in energy systems with imperfect foresight. IEW Proceedings IEA (Eds), Paris, France 2019;1.

Gielen D, Boshell F, Saygin D, Bazilian MD, Wagner N, Gorini R. The role of renewable energy in the global energy transformation. Energy Strategy Reviews 2019;24:38-50. URL: https://www.sciencedirect.com/science/article/pii/S2211467X19300082. doi:10. 1016/J.ESR. 2019.01.006.

Grant N, Hawkes A, Napp T, Gambhir A. The appropriate use of reference scenarios in mitigation analysis. Nature Climate Change 2020;URL: http://dx. doi .org/10.1038/s41558-020-0826-9. doi:10.1038/s41558-020-0826-9.

Guerra OJ, Zhang J, Eichman J, Denholm P, Kurtz J, Hodge BM. The value of seasonal energy storage technologies for the integration of wind and solar power. Energy Environ Sci 2020;13:190922. URL: http://dx.doi.org/10.1039/D0EE00771D. doi:10.1039/D0EE00771D.

Hand Mea. Renewable Electricity Futures Study. Technical Report; National Renewable Energy Laboratory, Golden, Colorado; 2012. URL: http://www.nrel.gov/analysis/re_futures/.

Hansen K, Mathiesen BV, Skov IR. Full energy system transition towards 100\% renewable energy in Germany in 2050. Renewable and Sustainable Energy Reviews 2019;102:1-13. URL: https: //www.sciencedirect.com/science/article/pii/S1364032118307913. doi:10.1016/j.rser. 2018.11.038. 
Howells M, Rogner H, Strachan N, Heaps C, Huntington H, Kypreos S, Hughes A, Silveira S, DeCarolis J, Bazillian M, Roehrl A. Osemosys: The open source energy modeling system: An introduction to its ethos, structure and development. Energy Policy 2011;39(10):5850 -70. URL: http://www.sciencedirect.com/science/article/pii/ S0301421511004897. doi:https://doi.org/10.1016/j.enpol.2011.06.033; sustainability of biofuels.

ICEF . Energy storage roadmap -. Technical Report November; Innovation for Cool Earth Forum (ICEF); 2017. URL: https://www.icef-forum.org/pdf/2018/roadmap/ Energy\{_\}Storage\{_\}Roadmap\{_\}ICEF2017.pdf.

IEA . Energy Technology Perspectives 2017 Catalysing Energy Technology Transformation. report; International Energy Agency; 2017.

International Energy Agency . Technology Roadmap - Energy Storage. Technical Report; International Energy Agency; 2014.

IRENA - Global Energy Transformation: The REmap transition pathway (Background report to 2019 Edition). Technical Report; International Renewable Energy Agency; 2019. URL: https://www.irena.org/-/media/Files/IRENA/Agency/Publication/2019/Apr/ IRENA\{_\}GET\{_\}REmap\{_\}pathway\{_\}2019.pdf.

IRENA and IEA . Perspectives for the Energy Transition - Investment Needs for a LowCarbon Energy System. Technical Report; IRENA and International Energy Agency (IEA); 2017. URL: http://www.irena.org/DocumentDownloads/Publications/Perspectives_for_ the_Energy_Transition_2017.pdf.

Khastieva D, Hesamzadeh MR, Vogelsang I, Rosellón J, Amelin M. Value of energy storage for transmission investments. Energy Strategy Reviews 2019;24:94-110. URL: https://www.sciencedirect.com/science/article/pii/S2211467X19300070. doi:10. 1016/J.ESR. 2019.01.008.

Koelbl BS, van den Broek M. A., Faaij APC, van Vuuren D. P. . Uncertainty in Carbon Capture and Storage (CCS) deployment projections: a cross-model comparison exercise. Climatic Change 2014;123(3-4):461-76. doi:10.1007/s10584-013-1050-7.

Koohi-Fayegh S, Rosen MA. A review of energy storage types, applications and recent developments. Journal of Energy Storage 2020;27(July 2019):101047. URL: https://doi .org/10.1016/j .est. 2019.101047. doi:10.1016/j. est.2019.101047. 
Krey V, Guo F, Kolp P, Zhou W, Schaeffer R, Awasthy A, Bertram C, de Boer HS, Fragkos P, Fujimori S, He C, Iyer G, Keramidas K, Köberle AC, Oshiro K, Reis LA, Shoai-Tehrani B, Vishwanathan S, Capros P, Drouet L, Edmonds JE, Garg A, Gernaat DEHJ, Jiang K, Kannavou M, Kitous A, Kriegler E, Luderer G, Mathur R, Muratori M, Sano F, van Vuuren DP. Looking under the hood: A comparison of techno-economic assumptions across national and global integrated assessment models. Energy 2019;172:1254-67. URL: http://www . sciencedirect. com/science/ article/pii/S0360544218325039. doi:https://doi .org/10.1016/j . energy . 2018.12 .131.

Langlois-Bertrand S, Vaillancourt K, Bahn O, Beaumier L, Mousseau N. Canadian Energy Outlook 2018 - Horizon 2050. Technical Report; Trottier Energy Institute and e3 Hub; 2018. URL: http://iet.polymtl.ca/en/energy-outlook/.

Lawrenz L, Xiong B, Lorenz L, Krumm A, Hosenfeld H, Burandt T, Löffler K, Oei PY, Von Hirschhausen C. Exploring energy pathways for the low-carbon transformation in india - a model-based analysis. Energies 2018;11(11). URL: https://www.mdpi.com/1996-1073/11/11/ 3001. doi:10.3390/en11113001.

Lazkano I, Nøstbakken L, Pelli M. From fossil fuels to renewables: The role of electricity storage. European Economic Review 2017;99:113-29. URL: https://www . sciencedirect.com/science/ article/pii/S0014292117300697. doi:10.1016/J .EUROECOREV . 2017.03.013.

Linn J, Shih JS. Do lower electricity storage costs reduce greenhouse gas emissions? Journal of Environmental Economics and Management 2019;96:130-58. URL: https://www. sciencedirect. com/science/article/pii/S0095069617304400.

Loffler K, Hainsch K, Burandt T, Oei PY, Kemfert C, Von Hirschhausen C. Designing a model for the global energy system - genesys-mod: An application of the open-source energy modeling system (osemosys). Energies 2017;10(10). URL: https://www.mdpi.com/1996-1073/10/10/1468. doi:10.3390/en10101468.

Loulou R, Labriet M. ETSAP-TIAM: the TIMES integrated assessment model Part I: Model structure. Computational Management Science 2008;5(1):7-40. URL: http://dx.doi .org/10.1007/ s10287-007-0046-z. doi:10.1007/s10287-007-0046-z.

Molar-Cruz A, Guillén B, Hamacher T. Cost-optimal regional deployment of renewable energy in the mexican electric power system. IEW Proceedings 2018, Gothenburg, Sweden 2018;

NEB - National Energy Board . Canada's Energy Future 2017 - Energy Supply and Demand Projections to 2040 - An Energy Market Assessment. Technical Report; NEB - National Energy Board; 2017. URL: https ://www . cer-rec.gc.ca/nrg/ntgrtd/ftr/2018/2018nrgftr-eng.pdf. 
Pachauri P, Meyer L. Climate Change 2014: Synthesis Report. Contribution of Working Groups I, II and III to the Fifth Assessment Report of the Intergovernmental Panel on Climate Change. Technical Report; IPCC; 2014. URL: http://dx.doi.org/10.1016/j.jclepro.2019.05.345.

Riahi K, van Vuuren DP, Kriegler E, Edmonds J, O'Neill BC, Fujimori S, Bauer N, Calvin K, Dellink R, Fricko O, Lutz W, Popp A, Cuaresma JC, KC S, Leimbach M, Jiang L, Kram T, Rao S, Emmerling J, Ebi K, Hasegawa T, Havlik P, Humpenöder F, Silva LAD, Smith S, Stehfest E, Bosetti V, Eom J, Gernaat D, Masui T, Rogelj J, Strefler J, Drouet L, Krey V, Luderer G, Harmsen M, Takahashi K, Baumstark L, Doelman JC, Kainuma M, Klimont Z, Marangoni G, Lotze-Campen H, Obersteiner M, Tabeau A, Tavoni M. The shared socioeconomic pathways and their energy, land use, and greenhouse gas emissions implications: An overview. Global Environmental Change 2017;42:153 -68. URL: http://www. sciencedirect.com/science/article/ pii/S0959378016300681. doi:https://doi.org/10.1016/j.gloenvcha.2016.05.009.

Ringkjøb HK, Haugan PM, Solbrekke IM. A review of modelling tools for energy and electricity systems with large shares of variable renewables. Renewable and Sustainable Energy Reviews 2018;96:440-59. URL: https://www.sciencedirect.com/science/article/pii/ S1364032118305690\{\#\}s0060. doi:10.1016/J.RSER.2018.08.002.

Rogelj J, Luderer G, Pietzcker RC, Kriegler E, Schaeffer M, Krey V, Riahi K. Energy system transformations for limiting end-of-century warming to below $1.5{ }^{\circ} \mathrm{C}$. Nature Climate Change 2015;5(6):519-27. doi:10.1038/nclimate2572.

Sachs J, Meng Y, Giarola S, Hawkes A. An agent-based model for energy investment decisions in the residential sector. Energy 2019;172:752 -68. URL: http://www. sciencedirect.com/science/ article/pii/S036054421930177X. doi:https://doi.org/10.1016/j.energy .2019.01.161.

Schmidt O, Hawkes A, Gambhir A, Staffell I. The future cost of electrical energy storage based on experience rates. Nature Energy 2017;2(8):17110. URL: https://doi.org/10.1038/nenergy . 2017.110. doi:10.1038/nenergy.2017.110.

Schmidt O, Melchior S, Hawkes A, Staffell I. Projecting the Future Levelized Cost of Electricity Storage Technologies. Joule 2019;3(1):81-100. URL: https://www.sciencedirect.com/science/ article/pii/S254243511830583X. doi:10.1016/J. JOULE.2018.12.008.

Segundo Sevilla FR, Parra D, Wyrsch N, Patel MK, Kienzle F, Korba P. Techno-economic analysis of battery storage and curtailment in a distribution grid with high PV penetration. Journal of Energy Storage 2018;17:73-83. URL: https://www. sciencedirect.com/science/article/pii/ S2352152X17302591. doi:10.1016/J .EST .2018.02.001. 
Speirs J, Jalil Vega F, Cooper J, Gerber Machado P, Giarola S, Brandon N, Hawkes A. The flexibility of gas: what is it worth? Technical Report; Imperial College London; 2020.

US Department of Energy . Global Energy Storage Database. Technical Report; US Department of Energy; 2019. URL: http://www.energystorageexchange.or.

Vaillancourt K, Bahn O, Frenette E, Sigvaldason O. Exploring deep decarbonization pathways to 2050 for canada using an optimization energy model framework. Applied Energy 2017;195:774-85. URL: http://www.sciencedirect.com/science/article/pii/ S0306261917303446. doi:https://doi .org/10.1016/j . apenergy . 2017.03.104.

Vaillancourt K, Bahn O, Sigvaldason O. The Canadian Contribution to Limiting Global Warming Below $2{ }^{\circ} \mathrm{C}$ : An Analysis of Technological Options and Regional Cooperation; Cham: Springer International Publishing. p. 227-44. URL: https://doi.org/10.1007/978-3-319-74424-7_14. doi:10.1007/978-3-319-74424-7_14.

Weyant JP. Introduction and overview. Energy Economics 2004;26(4):501-15. URL: http://www.sciencedirect.com/science/article/pii/S0140988304000301. doi:https: //doi.org/10.1016/j.eneco.2004.04.019.

Zakeri B, Syri S. Electrical energy storage systems: A comparative life cycle cost analysis. Renewable and Sustainable Energy Reviews 2015;42:569-96. URL: https://www. sciencedirect.com/ science/article/pii/S1364032114008284. doi:10.1016/J . RSER . 2014.10.011. 